\title{
Effect of Disulfide Cyclization of Ultrashort Cationic Lipopeptides on Antimicrobial Activity and Cytotoxicity
}

\author{
Damian Neubauer $^{1, *(1)}$, Maciej Jaśkiewicz ${ }^{1}\left({ }^{1}\right.$, Emilia Sikorska $^{2}(0)$, Sylwia Bartoszewska ${ }^{1}$, \\ Marta Bauer $^{1}$, Małgorzata Kapusta ${ }^{3}{ }^{(1)}$, Magdalena Narajczyk ${ }^{4}(-)$ and Wojciech Kamysz ${ }^{1}$ \\ 1 Department of Inorganic Chemistry, Faculty of Pharmacy, Medical University of Gdańsk, 80-416 Gdańsk, \\ Poland; mj@gumed.edu.pl (M.J.); sylwia.bartoszewska@gumed.edu.pl (S.B.); \\ marta.bauer@gumed.edu.pl (M.B.); wojciech.kamysz@gumed.edu.pl (W.K.) \\ 2 Department of Organic Chemistry, Faculty of Chemistry, University of Gdańsk, Wita Stwosza 63, \\ 80-308 Gdańsk, Poland; emilia.sikorska@ug.edu.pl \\ 3 Department of Plant Cytology and Embryology, Faculty of Biology, University of Gdańsk, Wita Stwosza 59, \\ 80-308 Gdańsk, Poland; malgorzata.kapusta@ug.edu.pl \\ 4 Laboratory of Electron Microscopy, Faculty of Biology, University of Gdańsk, Wita Stwosza 59, \\ 80-308 Gdańsk, Poland; magdalena.narajczyk@ug.edu.pl \\ * Correspondence: damian.neubauer@gumed.edu.pl; Tel.: +48-(58)-349-14-88
}

Received: 9 August 2020; Accepted: 22 September 2020; Published: 29 September 2020

\begin{abstract}
Ultrashort cationic lipopeptides (USCLs) are considered to be a promising class of antimicrobials with high activity against a broad-spectrum of microorganisms. However, the majority of these compounds are characterized by significant toxicity toward human cells, which hinders their potential application. To overcome those limitations, several approaches have been advanced. One of these is disulfide cyclization that has been shown to improve drug-like characteristics of peptides. In this article the effect of disulfide cyclization of the polar head of $N$-palmitoylated USCLs on in vitro biological activity has been studied. Lipopeptides used in this study consisted of three or four basic amino acids (lysine and arginine) and cystine in a cyclic peptide. In general, disulfide cyclization of the lipopeptides resulted in peptides with reduced cytotoxicity. Disulfide-cyclized USCLs exhibited improved selectivity between Candida sp., Gram-positive strains and normal cells in contrast to their linear counterparts. Interactions between selected USCLs and membranes were studied by molecular dynamics simulations using a coarse-grained force field. Moreover, membrane permeabilization properties and kinetics were examined. Fluorescence and transmission electron microscopy revealed damage to Candida cell membrane and organelles. Concluding, USCLs are strong membrane disruptors and disulfide cyclization of polar head can have a beneficial effect on its in vitro selectivity between Candida sp. and normal human cells.
\end{abstract}

Keywords: antifungal; antimicrobial peptides; lipopeptides; cationic lipopeptides; short lipopeptides; cyclic lipopeptides; disulfide cyclization; disulfide bridge; Candida

\section{Introduction}

The development of new antimicrobial agents seems to be fundamental, especially when considering dramatically increasing antimicrobial resistance [1]. This well-known fact encourages scientists to evaluate particular ideas in hope of getting closer to a solution. Nowadays, discovery of new antibiotics and chemotherapeutics has slowed down, although multidrug resistant pathogens are becoming more common. One of the promising classes of compounds is lipopeptides. Briefly, these molecules consist of a peptide linked to a fatty acid. The peptide residue is usually hydrophilic 
and charged, in contrast to the aliphatic lipid chain. Actually, there are only few lipopeptide antibiotics available on the market such as polymyxins, daptomycin, and echinocandins, which were originally isolated from microorganisms. Unfortunately, emergence of resistance against these antibiotics has also been reported [2-4]. In view of those reports, the scientific community has been forced to provide new insights into this issue and to intensify new drug development. To solve this problem, researchers have attempted to design molecules with beneficial properties to balance between toxicity and antimicrobial activity. Undoubtedly, ultrashort (up to 7 amino acid residues) cationic lipopeptides (USCLs) have been claimed to be effective antimicrobial agents [5-8]. These molecules have a detergent-like mode of action and their membrane-cation interactions partially rely on the electrostatic attraction between positively charged amino acid residues and negatively charged membrane components. The negatively charged cell surface results from the presence of lipoteichoic acid (cell wall of Gram-positive bacteria), various phospholipids in the membrane (i.e., phosphatidylserine, phosphatidylglycerol, phosphatidylinositol, and cardiolipin) as well as sialic acid (cell wall of Candida sp.) [9-12]. USCLs permeabilize membrane bilayers and consequently lead to cell death. Lipopeptides can exhibit, inter alia, anticancer, antibacterial, antifungal, antibiofilm, and antiadhesive activities but their application can be limited due to hemolytic potential and cytotoxicity against normal cells. Nevertheless, these properties make them perfect candidates for further studies and optimization of the structure. An appreciable antimicrobial activity of arginine- and lysine-based linear ultrashort cationic lipopeptides has been well documented [5,8,13-15]. A tetrapeptide containing four lysine residues and $N$-terminal hexadecenoic acid (palmitic acid, $\mathrm{C}_{16}$ ) with proven high antimicrobial activity was used as a reference lipopeptide $\left(\mathrm{C}_{16}-\mathrm{KKKK}^{-\mathrm{NH}_{2}}\right.$ also known as Pal/Palm-KKKK-NH$\left.{ }_{2}\right)[5,16,17]$. Interestingly, it has been shown that lysine-rich ultrashort $N$-palmitoylated lipopeptides can induce chemokine production in human macrophage-like THP-1 cells, this being beneficial for antibacterial therapy [18]. The mode of action of ultrashort cationic lipopeptides partially relies on electrostatic interactions with the pathogens' membrane. It has been shown that arginine is prone to forming extensive H-bonding with membrane phospholipids thus enhancing perturbations of the pathogen membrane [19]. The lysine side chain interacts with phosphate groups of the membrane, while the arginine guanidinium group can also associate with the glycerol residue of phospholipids [20]. To evaluate the influence of arginine residue, a series of analogs with different positions of this amino acid have been synthesized. A disulfide cyclization is another approach utilized for improvement of peptides' properties, and according to the literature, it can result in enhanced activity, selectivity, and stability [21]. Therefore, to learn how this modification can affect biological characteristics such as, antimicrobial activity against Gram-positive and Gram-negative bacteria, fungi (Candida sp.), and toxicity against human red blood cells (hRBCs), keratinocytes (HaCaT), and cervical cancer cells (HeLa); the set of cyclic analogs with intramolecular disulfide bridge has been synthesized. Cysteine residues were inserted at $N$ - and $C$ - terminal positions in the cyclic counterpart to create a loop with cystine and amino acids of the parent molecule between them. In effect, short cationic lipopeptides with arginine, cystine, lysine, hexadecenoic acid, and C-terminal amides were synthesized. The structures of selected lipopeptides used in this study are presented in Figure 1.

Ultrashort cationic lipopeptides (Figure 1A) and their cyclic analogs (Figure 1C) with disulfide motif were synthesized to find out how this modification can influence in vitro biological activity. Compounds with free sulfhydryl groups (Figure 1B) have not been studied herein due to their high susceptibility to oxidation [22]. 


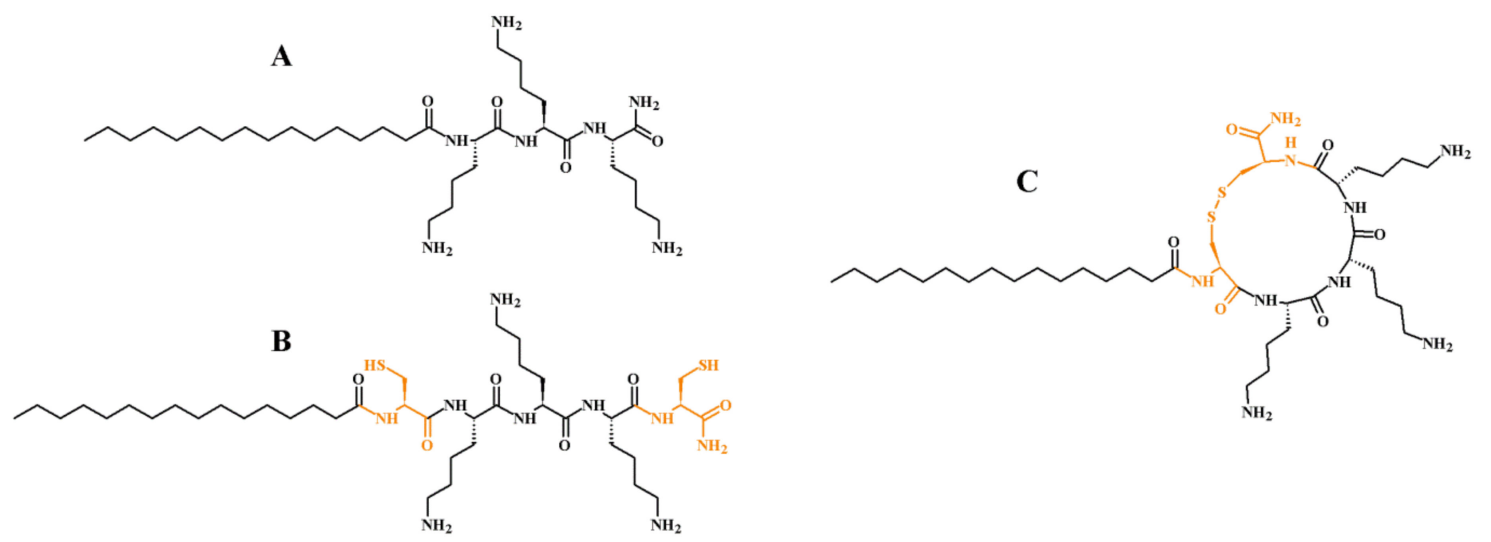

Figure 1. Linear lipopeptides $\mathrm{C}_{16}-\mathrm{KKK}^{-\mathrm{NH}_{2}}$ (A) parent molecule and its analog before (B) and after cyclization (C). Cysteine/cystine residues are colored orange.

\section{Results and Discussion}

\subsection{Determination of Peptide Hydrophobicity with RP-HPLC}

Lipopeptides were synthesized by solid-phase method using Fmoc chemistry. Peptides' hydrophobicity was evaluated by analytical reversed-phase high-performance liquid chromatography (RP-HPLC). Electrospray ionization mass spectrometry (ESI MS) in positive ion mode confirmed the identity of the purified peptides. Results of HPLC and MS analyses are presented in Table 1.

The peptides were analyzed by RP-HPLC to determine relative hydrophobicity vs. retention time of each compound. In general, more hydrophobic lipopeptides will elute later than hydrophilic ones. Using this simple rule enables comparison of hydrophobicity by reduced retention times $\left(\mathrm{t}_{\mathrm{R}}{ }_{\mathrm{R}}\right)$ and differences in retention time between the cyclic analog and its linear parent lipopeptide (Table 1). It can be deduced that the presence of cystine moiety has led to increased hydrophobicity. All cyclic lipopeptides are more hydrophobic than their linear counterparts but the effect of disulfide cyclization on retention is different in each pair. The highest increase in retention was noticed for the shortest lipopeptides L1 $\left(\mathrm{C}_{16}-\mathrm{KKK}-\mathrm{NH}_{2}\right)$ and $\mathrm{C} \mathbf{1}\left(\mathrm{C}_{16}-\mathrm{CKKKC}-\mathrm{NH}_{2}\right)$. The differences between lipopeptides with one arginine residue indicate that its position is crucial for retention and therefore hydrophobicity. To learn how the arginine position affects hydrophobicity, the retention time of compound $\mathbf{L} 2\left(\mathrm{C}_{16}-\mathrm{KKKK}^{-\mathrm{NH}_{2}}\right)$ or $\mathbf{C 2}$ $\left(\mathrm{C}_{16}\right.$-CKKKKC-NH $\left.\mathrm{N}_{2}\right)$ was subtracted from that of the lipopeptides with one arginine residue, linear (L3, L4, L5, L6) or cyclic (C3, C4, C5, C6), respectively. In Figure 2 the effect of arginine position on retention time is related to unsubstituted lipopeptide.

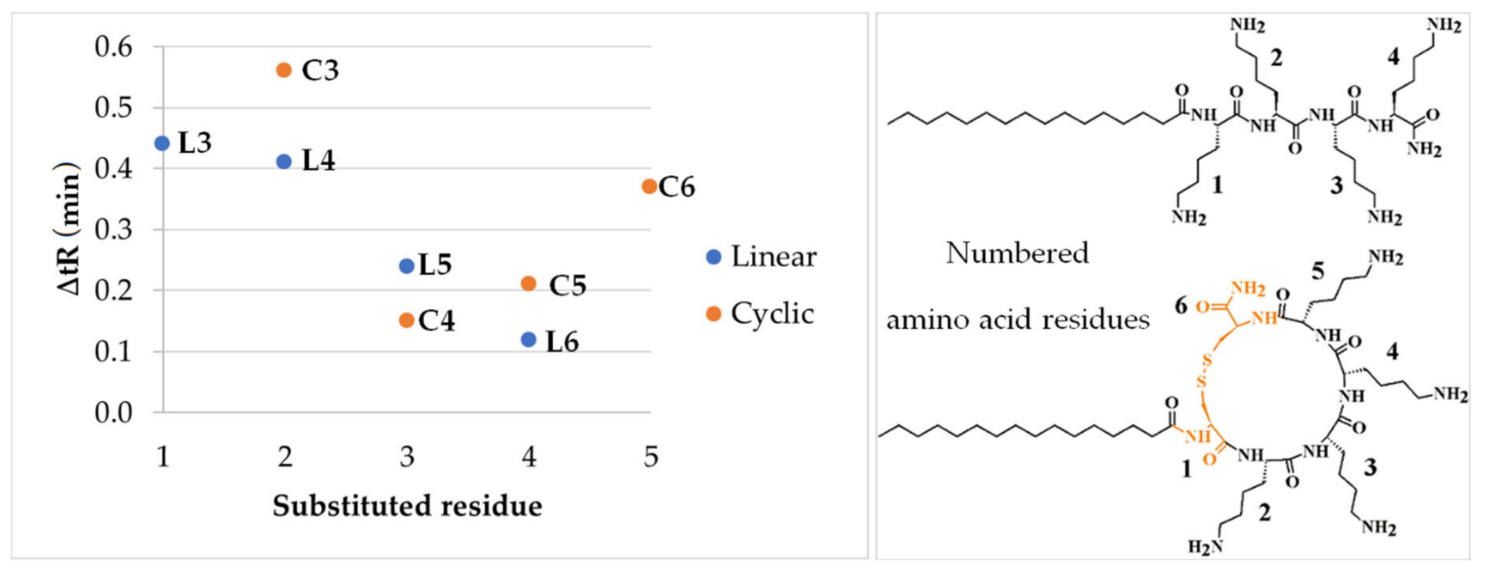

Figure 2. Effect of arginine position on retention behavior (left) related to unsubstituted lipopeptides (right). Cysteine/cystine residues are colored orange. 
Table 1. MS analysis, reduced retention time of lipopeptides $\left(t^{\prime} R\right)$, and calculated differences in retention time between the parent molecule and its analog $(\Delta t R)$.

\begin{tabular}{|c|c|c|c|c|c|c|c|c|c|}
\hline \multirow{2}{*}{ Peptide Code } & \multirow{2}{*}{ Sequence } & \multirow{2}{*}{ Av. Mass (Da) } & \multirow{2}{*}{ Monoisotopic Mass (Da) } & \multicolumn{3}{|c|}{ MS Analysis } & \multirow{2}{*}{ Net Charge } & \multirow{2}{*}{$\mathbf{t}_{R}^{\prime}(\min )$} & \multirow{2}{*}{$\Delta t_{R}(\min )$} \\
\hline & & & & $\mathrm{z}^{\mathrm{a}}$ & $m / z$ Calc. & $m / z$ Found & & & \\
\hline \multirow{3}{*}{ L1 } & \multirow{3}{*}{$\mathrm{C}_{16}-\mathrm{KKK}-\mathrm{NH}_{2}$} & \multirow{3}{*}{639.97} & \multirow{3}{*}{639.54} & 1 & 640.55 & 640.69 & \multirow{3}{*}{+3} & \multirow{3}{*}{16.14} & \multirow{6}{*}{+1.91} \\
\hline & & & & 2 & 320.78 & 321.01 & & & \\
\hline & & & & 3 & 214.19 & 214.39 & & & \\
\hline \multirow{3}{*}{$\mathrm{C} 1$} & \multirow{3}{*}{$\mathrm{C}_{16}-\mathrm{CKKKC}-\mathrm{NH}_{2}$} & \multirow{3}{*}{844.24} & \multirow{3}{*}{843.54} & 1 & 844.55 & 844.70 & \multirow{3}{*}{+3} & \multirow{3}{*}{18.05} & \\
\hline & & & & 2 & 422.78 & 423.04 & & & \\
\hline & & & & 3 & 282.19 & 282.43 & & & \\
\hline \multirow{4}{*}{ L2 } & \multirow{4}{*}{$\mathrm{C}_{16}-\mathrm{KKKK}-\mathrm{NH}_{2}$} & \multirow{4}{*}{768.14} & \multirow{4}{*}{767.64} & 1 & 768.64 & 768.86 & \multirow{4}{*}{+4} & \multirow{4}{*}{14.77} & \multirow{8}{*}{+1.18} \\
\hline & & & & 2 & 384.83 & 385.18 & & & \\
\hline & & & & 3 & 256.89 & 257.25 & & & \\
\hline & & & & 4 & 192.92 & - & & & \\
\hline \multirow{4}{*}{$\mathrm{C} 2$} & \multirow{4}{*}{$\mathrm{C}_{16}-\mathrm{CKKKKC-NH} \mathrm{N}_{2}$} & \multirow{4}{*}{972.42} & \multirow{4}{*}{971.64} & 1 & 972.65 & 972.75 & & & \\
\hline & & & & 2 & 486.83 & 487.19 & +4 & 1505 & \\
\hline & & & & 3 & 324.89 & 325.20 & +4 & 15.95 & \\
\hline & & & & 4 & 243.92 & - & & & \\
\hline & & & & 1 & 796.65 & 796.84 & & & \\
\hline 3 & $\mathrm{C}_{-}-\mathrm{RKKK}-\mathrm{NH}$ & 79615 & 70564 & 2 & 398.83 & 399.14 & +4 & 1521 & \\
\hline Lo & 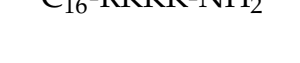 & 190.10 & 190.04 & 3 & 266.22 & 266.59 & +4 & 10.21 & \\
\hline & & & & 4 & 199.92 & - & & & +130 \\
\hline & & & & 1 & 1000.65 & 1000.83 & & & \\
\hline$C_{3}$ & $\mathrm{C}_{1-\mathrm{C}} \mathrm{CRKKKC}-\mathrm{NH}$ & 100043 & 09965 & 2 & 500.83 & 501.19 & +4 & 1651 & \\
\hline Co & 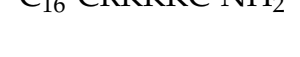 & 1000.45 & (599.00 & 3 & 334.22 & 334.62 & +4 & 10.01 & \\
\hline & & & & 4 & 250.92 & - & & & \\
\hline
\end{tabular}


Table 1. Cont.

\begin{tabular}{|c|c|c|c|c|c|c|c|c|c|}
\hline \multirow{2}{*}{ Peptide Code } & \multirow{2}{*}{ Sequence } & \multirow{2}{*}{ Av. Mass (Da) } & \multirow{2}{*}{ Monoisotopic Mass (Da) } & \multicolumn{3}{|c|}{ MS Analysis } & \multirow{2}{*}{ Net Charge } & \multirow{2}{*}{$\mathbf{t}_{\mathbf{R}}^{\prime}(\min )$} & \multirow{2}{*}{$\Delta t_{R}(\min ) *$} \\
\hline & & & & $z^{a}$ & $m / z$ Calc. & $m / z$ Found & & & \\
\hline \multirow{4}{*}{ L4 } & \multirow{4}{*}{$\mathrm{C}_{16}-\mathrm{KRKK} \mathrm{NH}_{2}$} & \multirow{4}{*}{796.15} & \multirow{4}{*}{795.64} & 1 & 796.65 & 769.95 & \multirow{4}{*}{+4} & \multirow{4}{*}{15.18} & \multirow{8}{*}{+0.92} \\
\hline & & & & 2 & 398.83 & 399.27 & & & \\
\hline & & & & 3 & 266.22 & 266.54 & & & \\
\hline & & & & 4 & 199.92 & - & & & \\
\hline \multirow{4}{*}{$\mathrm{C} 4$} & \multirow{4}{*}{$\mathrm{C}_{16}-\mathrm{CKRKKC}-\mathrm{NH}_{2}$} & \multirow{4}{*}{1000.43} & \multirow{4}{*}{999.65} & 1 & 1000.65 & 1000.86 & \multirow{4}{*}{+4} & \multirow{4}{*}{16.10} & \\
\hline & & & & 2 & 500.83 & 501.07 & & & \\
\hline & & & & 3 & 334.22 & 334.68 & & & \\
\hline & & & & 4 & 250.92 & - & & & \\
\hline \multirow{4}{*}{ L5 } & \multirow{4}{*}{$\mathrm{C}_{16}-\mathrm{KKRK}-\mathrm{NH}_{2}$} & \multirow{4}{*}{796.15} & \multirow{4}{*}{795.64} & 1 & 796.65 & 796.80 & \multirow{4}{*}{+4} & \multirow{4}{*}{15.01} & \\
\hline & & & & 2 & 398.83 & 399.24 & & & \\
\hline & & & & 3 & 266.22 & 266.53 & & & \\
\hline & & & & 4 & 199.92 & - & & & +1.15 \\
\hline \multirow{4}{*}{ C5 } & \multirow{4}{*}{$\mathrm{C}_{16}-\mathrm{CKKRKC- \textrm {NH } _ { 2 }}$} & \multirow{4}{*}{1000.43} & \multirow{4}{*}{999.65} & 1 & 1000.65 & 1000.77 & \multirow{4}{*}{+4} & \multirow{4}{*}{16.16} & \\
\hline & & & & 2 & 500.83 & 501.11 & & & \\
\hline & & & & 3 & 334.22 & 334.45 & & & \\
\hline & & & & 4 & 250.92 & - & & & \\
\hline
\end{tabular}


Table 1. Cont.

\begin{tabular}{|c|c|c|c|c|c|c|c|c|c|}
\hline \multirow{2}{*}{ Peptide Code } & \multirow{2}{*}{ Sequence } & \multirow{2}{*}{ Av. Mass (Da) } & \multirow{2}{*}{ Monoisotopic Mass (Da) } & \multicolumn{3}{|c|}{ MS Analysis } & \multirow{2}{*}{ Net Charge } & \multirow{2}{*}{$\mathbf{t}_{\mathrm{R}}^{\prime}(\min )$} & \multirow{2}{*}{$\Delta t_{R}(\min ) *$} \\
\hline & & & & $\mathrm{z}^{\mathrm{a}}$ & $m / z$ Calc. & $m / z$ Found & & & \\
\hline \multirow{4}{*}{ L6 } & \multirow{4}{*}{$\mathrm{C}_{16}-\mathrm{KKKR}-\mathrm{NH}_{2}$} & \multirow{4}{*}{796.15} & \multirow{4}{*}{795.64} & 1 & 796.65 & 796.81 & \multirow{4}{*}{+4} & \multirow{4}{*}{14.89} & \multirow{8}{*}{+1.43} \\
\hline & & & & 2 & 398.83 & 399.11 & & & \\
\hline & & & & 3 & 266.22 & 266.42 & & & \\
\hline & & & & 4 & 199.92 & - & & & \\
\hline \multirow{4}{*}{ C6 } & \multirow{4}{*}{$\mathrm{C}_{16}-\mathrm{CKKKRC}-\mathrm{NH}_{2}$} & \multirow{4}{*}{1000.43} & \multirow{4}{*}{999.65} & 1 & 1000.65 & 1000.80 & \multirow{4}{*}{+4} & \multirow{4}{*}{16.32} & \\
\hline & & & & 2 & 500.83 & 501.11 & & & \\
\hline & & & & 3 & 334.22 & 334.51 & & & \\
\hline & & & & 4 & 250.92 & 251.11 & & & \\
\hline \multirow{4}{*}{ L7 } & \multirow{4}{*}{$\mathrm{C}_{16}-\mathrm{RRKK} \mathrm{NH}_{2}$} & \multirow{4}{*}{824.17} & \multirow{4}{*}{823.65} & 1 & 824.66 & 824.87 & \multirow{4}{*}{+4} & \multirow{4}{*}{15.58} & \multirow{8}{*}{+1.25} \\
\hline & & & & 2 & 412.83 & 413.21 & & & \\
\hline & & & & 3 & 275.56 & 276.02 & & & \\
\hline & & & & 4 & 206.92 & - & & & \\
\hline \multirow{4}{*}{$\mathrm{C} 7$} & \multirow{4}{*}{$\mathrm{C}_{16}$-CRRKKC-NH${ }_{2}$} & \multirow{4}{*}{1028.44} & \multirow{4}{*}{1027.65} & 1 & 1028.66 & 1028.79 & \multirow{4}{*}{+4} & \multirow{4}{*}{16.83} & \\
\hline & & & & 2 & 514.83 & 515.20 & & & \\
\hline & & & & 3 & 343.56 & 343.89 & & & \\
\hline & & & & 4 & 257.92 & - & & & \\
\hline
\end{tabular}


Changes in the retention $(\Delta t R)$ have different patterns in the cyclic and linear lipopeptides. In the linear peptides, when arginine residue was closer to the fatty acid chain, an increase in hydrophobicity was higher (Figure 2, $\Delta \mathrm{tR}$ of compounds L3, L4, L5, and L6). In cyclic analogs, $\Delta \mathrm{tR}$ is the lowest for the third substituted residue, but when the fourth and fifth residues are substituted, $\Delta t R$ steeply increases. Presumably, this phenomenon can be explained in terms of the different chemical microenvironment of arginine. Residues 2 and 5 are much closer to the hydrophobic region than residues 3 and 4 . In this case, it seems likely that proximity of the fatty acid chain and cysteine, as a hydrophobic part of the molecule, plays a pivotal role (Figure 2) [23]. Moreover, it has been possible to verify the additive nature of the effects of lysine substitution by arginine on hydrophobicity using the differences in $\Delta \mathrm{tR}$. As the substitution with arginine gives analogs with an increased retention time, it can be deduced that $\mathrm{t}_{\mathrm{R}}$ of $\mathbf{L 7}\left(\mathrm{C}_{16}-\mathrm{RRKK}-\mathrm{NH}_{2}\right)$ and $\mathbf{C 7}\left(\mathrm{C}_{16}-\mathrm{CRRKKC}-\mathrm{NH}_{2}\right)$ must be higher than that of a single substituted compound. To calculate retention time $\left(\mathrm{t}^{\prime} \mathrm{R}\right.$ calc. $)$ of disubstituted lipopeptides (L7 and C7), the differences in $t^{\prime}$ between unsubstituted species (L2 or C2) and monosubstituted ones (L3, C3, L4, C4) were added to the retention of unsubstituted compound.

Hence,

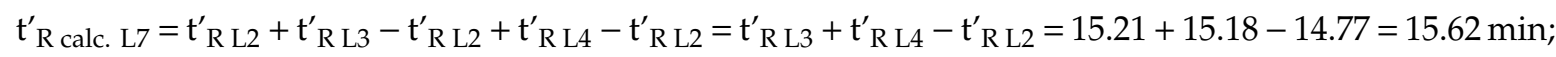

$\mathrm{t}_{\mathrm{R}}^{\prime} \operatorname{exp.~L7}=15.58 \mathrm{~min} ;$

$\mathrm{t}_{\mathrm{R} \text { calc. L7 }}^{\prime}-\mathrm{t}_{\mathrm{R} \text { exp. } \mathrm{L} 7}^{\prime}=0.04$ min;

$\mathrm{t}_{\mathrm{R} \text { calc. } \mathrm{C} 7}=\mathrm{t}_{\mathrm{R} C 2}^{\prime}+\mathrm{t}_{\mathrm{R} C 3}^{\prime}-\mathrm{t}_{\mathrm{R} C 2}^{\prime}+\mathrm{t}_{\mathrm{R} C 4}^{\prime}-\mathrm{t}_{\mathrm{R} C 2}^{\prime}=\mathrm{t}_{\mathrm{R} C 3}^{\prime}+\mathrm{t}_{\mathrm{R} C 4}^{\prime}-\mathrm{t}_{\mathrm{R} C 2}^{\prime}=16.51+16.10-15.95=16.66 \mathrm{~min} ;$

$\mathrm{t}_{\mathrm{R}}^{\prime} \operatorname{exp.} \mathrm{C7}=16.83 \mathrm{~min} ;$

$\mathrm{t}_{\mathrm{R} \text { calc. C7 }}^{\prime}-\mathrm{t}_{\mathrm{R} \text { exp. C7 }}^{\prime}=-0.17 \mathrm{~min}$.

It can be speculated that the effect of lysine substitution with arginine on hydrophobicity of linear lipopeptide is additive $\left(t^{\prime} R\right.$ calc. L7 Vs. $t_{R}^{\prime}$ exp. L7). The difference between calculated and experimental retention times seems to be relatively small. The maximum coefficient of variation in this study was $0.25 \%$, thus giving an experimental variance of ca. $0.04 \mathrm{~min}$. However, in the case of cyclic lipopeptide (C7) a noticeable inconsistence of calculations with experiment $\left(\mathrm{t}^{\prime} \mathrm{R}\right.$ exp. $)$ has been found, probably due to the consequence of interactions between neighboring arginine side-chains in disulfide-constrained peptide loop. Clusters, rings, and strings of arginine residues were found in many proteins. Interactions between guanidinium cations in arginine side-chain are known to influence the structure and stability of macromolecules [24]. Moreover, arginine was found to exhibit hydrophobic stacking, unlike lysine residues, due to energetically favorable interactions between staggered guanidinium cations $[25,26]$. Arginine-arginine pairing can play a crucial role in interactions of peptides and proteins such as oligomerization $[27,28]$. To sum up, it can be stated that it is highly likely that interactions between arginine residues are occurring in the peptides and are different in the cyclic analogs and in the linear counterpart.

\subsection{Antimicrobial Activity of Lipopeptides}

Minimum inhibitory concentrations (MICs) of lipopeptides were determined against planktonic cultures of bacteria and fungi. The results are shown in Table 2.

In the present study, all synthesized lipopeptides exhibited antimicrobial activity. Cyclization leads to compounds with similar activity against Gram-positive strains (insignificant differences). Peptides C1 and $\mathbf{C} 5$ were more active against S. epidermidis and S. aureus than their linear parent molecules. It should be noted that solubility of the compounds can be crucial for their activity. Our previous study showed that some disulfide-cyclized lipopeptides have higher antistaphylococcal activity when dissolved in aqueous solutions of acetic acid/BSA (0.01\% and $0.2 \%$, respectively) than in PBS (stock solution) [29]. Moreover, Gram-negative strains appeared to be more resistant to lipopeptides than Gram-positive bacteria and fungi, this being consistent with previous studies on lipopeptides [8,14]. Furthermore, cyclic analogs had a noticeably lower activity than the linear ones (even fourfold). The MICs of lipopeptides against Gram-negative strains ranged between 8 and $512 \mu \mathrm{g} / \mathrm{mL}$. In general, P. aeruginosa 
seem to be least susceptible to USCLs. Moreover, it is noteworthy that additional lysine residue (L2, C2 vs. L1, C1, respectively) gave compounds with a higher net charge (+4) and simultaneously improved antimicrobial activity against $P$. aeruginosa (contrary to E. coli). However, substitutions with arginine resulted in compounds with considerably lower activity against this strain. Reduced susceptibility of Gram-negative bacteria to cationic lipopeptides is mainly associated with the nature of their outer membrane. For instance, $P$. aeruginosa is equipped with a two-component regulatory system, PmrA-PmrB, that controls resistance to cationic antimicrobial peptides and lipopeptides (polymyxin B). Its activation results in incorporation of 4-aminoarabinose (L-Ara4N) into lipid A thus increasing overall charge of lipopolysaccharide (LPS) and restricting interactions between LPS and cationic lipopeptides [30,31]. Moreover, resistance to cationic antimicrobial peptides is associated with palmitoylation of lipid A in both E. coli and P. aeruginosa [32,33]. It has been documented that E. coli resistance to antimicrobial peptides relies partially on the outer membrane protease OmpT [34,35]. Moreover, it has been hypothesized that USCLs can form aggregates reducing their antimicrobial activity due to restrained translocation through LPS. This phenomenon is associated with the length of the fatty acid chain and composition of amino acids [36]. Both the polar head group and the fatty acid chain have a great impact on lipopeptide self-assembly. The structure and length of the fatty acid chain and amino acid composition of USCLs can affect both the oligomerization process (in solution or bound to cell) and biological activity [16,37-40].

Table 2. Antimicrobial activity of lipopeptides.

\begin{tabular}{|c|c|c|c|c|c|c|c|c|}
\hline \multirow{2}{*}{$\begin{array}{l}\text { Peptide } \\
\text { Code }\end{array}$} & \multicolumn{8}{|c|}{$\mathrm{MIC}(\mu \mathrm{g} / \mathrm{mL})$} \\
\hline & $\begin{array}{c}S . \\
\text { aureus }\end{array}$ & $\begin{array}{c}S . \\
\text { epidermidis }\end{array}$ & $\begin{array}{c}E . \\
\text { coli }\end{array}$ & $\begin{array}{c}P . \\
\text { aeruginosa }\end{array}$ & $\begin{array}{c}C . \\
\text { albicans }\end{array}$ & $\begin{array}{c}C . \\
\text { glabrata }\end{array}$ & $\begin{array}{c}C . \\
\text { lipolytica }\end{array}$ & $\begin{array}{c}C . \\
\text { tropicalis }\end{array}$ \\
\hline L1 & $32 *$ & 8 & 16 & 64 & 32 & 32 & 16 & 8 \\
\hline $\mathrm{C} 1$ & $8^{*}$ & 4 & 16 & 256 & 8 & 4 & 4 & 4 \\
\hline L2 & 16 & 8 & 32 & 16 & 32 & 64 & 8 & 4 \\
\hline $\mathrm{C} 2$ & 32 & 8 & 64 & 32 & 4 & 4 & 2 & 2 \\
\hline L3 & $16^{*}$ & 8 & 8 & 32 & 8 & 64 & 8 & 8 \\
\hline $\mathrm{C} 3$ & $8^{*}$ & 8 & 16 & 512 & 2 & 8 & 4 & 2 \\
\hline L4 & 8 & 8 & 8 & 32 & 16 & 32 & 1 & 2 \\
\hline $\mathrm{C} 4$ & 16 & 8 & 32 & 256 & 2 & 4 & 1 & 2 \\
\hline L5 & $16^{*}$ & 8 & 8 & 64 & 32 & 64 & 8 & 8 \\
\hline $\mathrm{C} 5$ & $8^{*}$ & 4 & 16 & 256 & 16 & 8 & 4 & 4 \\
\hline L6 & $16^{*}$ & 4 & 8 & 64 & 32 & 64 & 8 & 8 \\
\hline C6 & $16^{*}$ & 8 & 32 & 128 & 4 & 4 & 2 & 2 \\
\hline L7 & 4 & 4 & 8 & 64 & 32 & 16 & 8 & 8 \\
\hline $\mathrm{C} 7$ & 8 & 4 & 16 & 256 & 16 & 4 & 4 & 4 \\
\hline $\mathrm{L}_{\text {mean }} * *$ & 15.4 & 6.9 & $12.6^{\dagger}$ & $48.0^{\dagger}$ & $26.3^{+}$ & $48.0^{\dagger}$ & $8.1^{+}$ & $6.6^{+}$ \\
\hline $\mathrm{C}_{\text {mean }}$ ** & 13.7 & 6.3 & $27.4^{\dagger}$ & $242.3^{+}$ & $7.4^{+}$ & $5.1^{\dagger}$ & $3.0^{+}$ & $2.9^{+}$ \\
\hline$p$-value & 0.633 & 0.701 & 0.030 & 0.015 & 0.009 & 0.002 & 0.025 & 0.025 \\
\hline
\end{tabular}

* These analyses were performed by our group in the previous study [29]; ** arithmetic mean of Minimum inhibitory concentrations (MIC) for linear (L) and cyclic (C) lipopeptides. $+p$-values for significant differences $(p<0.05)$.

In the present study, the lipopeptides were highly active against Candida strains. It has been shown that in some lipopeptides, arginine residues induced a stronger binding to the fungal model membrane than their lysine counterparts did [41]. In this study the effect of substitution of lysine with arginine residue(s) (lipopeptides L3-L7 and C3-C7) on antifungal activity was position-dependent (linear and cyclic USCLs as compared to $\mathbf{L} 2$ and $\mathbf{C}$, respectively). It seems likely that a second amino acid residue is optimal for this substitution (L4, C4 vs. L2, C2) due to beneficial effect in antifungal activity in both the linear and cyclic USCLs (Table 2). Antifungal activity of the cyclic lipopeptides was usually 
substantially higher than that of the linear molecules (up to fourfold). Interestingly, all compounds were highly active against $C$. lipolytica and $C$. tropicalis $(1-16 \mu \mathrm{g} / \mathrm{mL})$. Furthermore, antifungal activity against $C$. albicans and C. glabrata of the linear lipopeptides $(8-64 \mu \mathrm{g} / \mathrm{mL})$ was reinforced upon disulfide cyclization $(2-16 \mu \mathrm{g} / \mathrm{mL})$. In the Candida strains there are two transporter families capable of transportation of peptides into the cell. Peptide transporters (PTR) are able to carry small peptides consisting of 2-3 amino acid residues into the cell. Oligopeptide transporters (OPT) are engaged in uptake of longer peptides. Some antifungal peptides need to be transported into yeast cells to induce the antifungal effect (e.g., histatin 5, Hst 5). It has been demonstrated that cysteine-rich human $\beta$-defensins require Ssa1/2 cell wall heat shock proteins for inducing antifungal activity. The same proteins are initially binding histatin 5 [42]. In fact, peptide transport deficiency can result in the resistance to some antifungals [43]. Another study revealed that polycationic Hst 5 (net charge +12 ) is transported through yeast polyamine transporters, Dur3p and Dur31p, and this process is energy-dependent [44]. It was shown that intracellular accumulation of cationic arginine-rich salmon protamine is required for fungicidal activity and involves cell energy. Moreover, disulfide cyclization of protamine leads to a cyclic analog with a five-fold higher anticandidal activity [45]. A hypothesis claims that disulfide cyclized USCLs can be transported into yeast cells through a transporter (OPT or a polyamine) and degrade cell membrane and its interior to cause cell death.

When a peptide is cyclic its antifungal activity is usually remarkably higher than that of the antibacterial activity as compared that of the linear parent molecules. The differences in antifungal and antibacterial (Gram-negative) activities between the cyclic and linear lipopeptides are statistically significant $(p<0.05)$. Makovitzki et al. have reported a high antimicrobial activity of $\mathrm{C}_{16}-\mathrm{KKkK}^{-\mathrm{NH}_{2}}$ (originally written as $\mathrm{C}_{16}-\mathrm{KKKK}-\mathrm{NH}_{2} ; \mathrm{k} / \mathrm{K}$-D-enantiomer) against $P$. aeruginosa, E. coli, and S. aureus (3-6.25 $\mu \mathrm{M}$; approx. 2.3-4.8 $\mu \mathrm{g} / \mathrm{mL}$ ) being similar to that of lipopeptide 3. However, different reference strains of $S$. aureus and P. aeruginosa, distinct culture media (LB) and the D-enantiomer of lysine were used, this explaining inconsistence with our results, especially those concerning Gram-negative strains $(16-32 \mu \mathrm{g} / \mathrm{mL}$ ) [5]. Again, similar results were obtained with C. albicans (ATCC 10231). The determined MICs were $25 \mu \mathrm{M}$ (approx. $19.2 \mu \mathrm{g} / \mathrm{mL}$ ) and $32 \mu \mathrm{g} / \mathrm{mL}$ by Makovitzki et al. and in this study, respectively. Greber et al. presented results of antimicrobial activity of $\mathrm{C}_{16}-\mathrm{KKK}^{-\mathrm{NH}_{2}}(\mathbf{L 1})$ and $\mathrm{C}_{16}-\mathrm{KKKK}-\mathrm{NH}_{2}(\mathbf{L} 2)$ against bacterial and fungal strains which only partially agree with those of this study [17]. However, the main difference in this study is related to E. coli, P. aeruginosa, and C. albicans strains, whose MICs are even three-fold higher for bacteria and two-fold lower for fungi. The discrepancies in antifungal activity can be explained in terms of different culture media applied for susceptibility testing. It has been well documented, also in our previous article, that the medium and cultivating conditions are critical for the determined values [29]. Different experimental conditions (initial inoculum of bacteria) can account for the observed divergence.

\subsection{Antibiofilm Activity}

Biofilms can be defined as complex conglomerates of microorganisms characterized by a significant resistance toward antibiotics. It has been reported that biofilms can be 1000 -fold more resistant to antibiotics compared to that of planktonic cultures. Moreover, severe infections are often associated with biofilm formation and therefore, it seems desirable to develop new effective treatment options against this structure [46]. In view of the above, we decided to test lipopeptides in antibiofilm assay. The results of minimum biofilm eradication concentrations (MBECs) are presented in Table 3.

As a result, few cyclic lipopeptides were characterized by identical MIC and MBEC values against some Gram-negative strains (compounds C1, C2, C5, and C7) in contrast to the linear ones. Furthermore, cyclic compounds C2, C4, and C7 had identical antibiofilm activity against bacteria as did their parent molecules. Generally, cyclic lipopeptides appeared to have even twice as high antibiofilm activity against Candida strains than linear lipopeptides except those with net charge +3 (L1, C1; equal MBEC values). In another study, lipopeptides $\mathrm{C}_{16}-\mathrm{KK}-\mathrm{NH}_{2}$ and $\mathrm{C}_{16}-\mathrm{RR}^{-\mathrm{NH}_{2}}$ exhibited high antimicrobial activity (MIC between 4 and $32 \mu \mathrm{g} / \mathrm{mL}$ ) and substantially lower antibiofilm potential 
(MBEC between 32 and $>512 \mu \mathrm{g} / \mathrm{mL}$ ) against bacteria (S. aureus, S. epidermidis, E. coli, P. aeruginosa). This general observation is comparable with that of this study [47]. Presumably, the increasing net charge improves antibiofilm activity of lipopeptides. For instance, our previous report indicated that cyclic lipopeptides exhibited higher antibiofilm activity against Staphylococcus strains (both the reference and clinical ones) in comparison to that of the linear molecules, but only when the compounds were dissolved in $\mathrm{AcOH} / \mathrm{BSA}(0.01 \%$ and $0.2 \%$, respectively) solution [29]. As the biofilm formation starts when microbial cells adhere to a surface, in terms of prophylaxis, it is desirable to protect materials from pathogen colonization, especially when taking into account its high resistance to antimicrobials. It is well documented that biosurfactants, as well as the linear and cyclic lipopeptides with palmitic acid, may prevent biofilm formation [48-50]. For this reason, biofilm-inhibiting properties of lipopeptides were also examined and the minimum biofilm inhibitory concentrations (MBICs) were determined. The results of MBICs are presented in Table 4.

Table 3. Antibiofilm activity of lipopeptides.

\begin{tabular}{|c|c|c|c|c|c|c|c|c|}
\hline \multirow{2}{*}{$\begin{array}{l}\text { Peptide } \\
\text { Code }\end{array}$} & \multicolumn{8}{|c|}{ MBEC $(\mu \mathrm{g} / \mathrm{mL})$} \\
\hline & $\begin{array}{c}\text { S. } \\
\text { aureus }\end{array}$ & $\begin{array}{c}S . \\
\text { epidermidis }\end{array}$ & $\begin{array}{c}E . \\
\text { coli }\end{array}$ & $\begin{array}{c}P . \\
\text { aeruginosa }\end{array}$ & $\begin{array}{c}\text { C. } \\
\text { albicans }\end{array}$ & $\begin{array}{c}\text { C. } \\
\text { glabrata }\end{array}$ & $\begin{array}{c}\text { C. } \\
\text { lipolytica }\end{array}$ & $\begin{array}{c}\text { C. } \\
\text { tropicalis }\end{array}$ \\
\hline L1 & $64 *$ & 32 & 64 & 128 & 256 & 256 & 64 & 128 \\
\hline $\mathrm{C} 1$ & $64 *$ & 32 & 256 & 256 & 256 & 256 & 64 & 128 \\
\hline L2 & 64 & 32 & 64 & $>256$ & 256 & 256 & 64 & 128 \\
\hline $\mathrm{C} 2$ & 64 & 32 & 64 & $>256$ & 64 & 64 & 16 & 32 \\
\hline L3 & $64 *$ & 32 & 128 & 256 & 128 & 128 & 32 & 32 \\
\hline C3 & $128^{*}$ & 128 & 256 & 256 & 32 & 32 & 16 & 32 \\
\hline L4 & 64 & 32 & 64 & $>256$ & 128 & 128 & 32 & 64 \\
\hline $\mathrm{C} 4$ & 64 & 32 & 64 & $>256$ & 32 & 64 & 16 & 32 \\
\hline L5 & $32 *$ & 32 & 64 & 256 & 256 & 256 & 64 & 128 \\
\hline C5 & $128 *$ & 64 & 128 & 256 & 64 & 64 & 16 & 32 \\
\hline L6 & $32 *$ & 32 & 256 & 256 & 128 & 128 & 32 & 128 \\
\hline C6 & $64 *$ & 128 & $>256$ & $>256$ & 64 & 64 & 16 & 32 \\
\hline L7 & 128 & 64 & 256 & 256 & 64 & 128 & 16 & 64 \\
\hline $\mathrm{C} 7$ & 128 & 64 & 256 & 256 & 64 & 64 & 16 & 32 \\
\hline $\mathrm{L}_{\text {mean }} * *$ & 64.0 & 36.6 & - & - & $173.7^{+}$ & $182.9^{+}$ & $43.4^{+}$ & $96.0^{+}$ \\
\hline $\mathrm{C}_{\text {mean }} * *$ & 91.4 & 68.6 & - & - & $82.3^{\dagger}$ & $86.9^{\dagger}$ & $22.9^{+}$ & $45.7^{\dagger}$ \\
\hline$p$-value & 0.131 & 0.160 & - & - & 0.035 & 0.018 & 0.048 & 0.041 \\
\hline
\end{tabular}

* These analyses were performed by our group in the previous study [29]; ** arithmetic mean of minimum biofilm eradication concentrations (MBEC) for linear (L) and cyclic (C) lipopeptides. $+p$-values for significant differences $(p<0.05)$.

Table 4. Biofilm inhibitory activity of lipopeptides.

\begin{tabular}{ccccccccc}
\hline \multirow{2}{*}{$\begin{array}{c}\text { Peptide } \\
\text { Code }\end{array}$} & $\begin{array}{c}\text { S. } \\
\text { aureus }\end{array}$ & $\begin{array}{c}\text { S. } \\
\text { epidermidis }\end{array}$ & $\begin{array}{c}\text { E. } \\
\text { coli }\end{array}$ & $\begin{array}{c}\boldsymbol{P} \text {. } \\
\text { aeruginosa }\end{array}$ & $\begin{array}{c}\text { C. } \\
\text { albicans }\end{array}$ & $\begin{array}{c}\text { C. } \\
\text { glabrata }\end{array}$ & $\begin{array}{c}\text { C. } \\
\text { lipolytica }\end{array}$ & $\begin{array}{c}\text { C. } \\
\text { tropicalis }\end{array}$ \\
\hline L1 & 32 & 16 & 32 & 32 & 128 & 128 & 32 & 16 \\
C1 & 16 & 16 & 64 & 128 & 32 & 32 & 16 & 32 \\
\hline L2 & 32 & 16 & 32 & 64 & 128 & 128 & 32 & 16 \\
C2 & 16 & 4 & 32 & 64 & 16 & 32 & 8 & 8 \\
\hline L3 & 32 & 16 & 32 & 64 & 64 & 64 & 16 & 16 \\
C3 & 16 & 8 & 64 & 64 & 8 & 8 & 2 & 4 \\
\hline
\end{tabular}


Table 4. Cont.

\begin{tabular}{|c|c|c|c|c|c|c|c|c|}
\hline \multirow{2}{*}{$\begin{array}{l}\text { Peptide } \\
\text { Code }\end{array}$} & \multicolumn{8}{|c|}{$\operatorname{MBIC}(\mu \mathrm{g} / \mathrm{mL})$} \\
\hline & $\begin{array}{c}\text { S. } \\
\text { aureus }\end{array}$ & $\begin{array}{c}S . \\
\text { epidermidis }\end{array}$ & $\begin{array}{c}E . \\
\text { coli }\end{array}$ & $\begin{array}{c}P . \\
\text { aeruginosa }\end{array}$ & $\begin{array}{c}C . \\
\text { albicans }\end{array}$ & $\begin{array}{c}\text { C. } \\
\text { glabrata }\end{array}$ & $\begin{array}{c}\text { C. } \\
\text { lipolytica }\end{array}$ & $\begin{array}{c}\text { C. } \\
\text { tropicalis }\end{array}$ \\
\hline L4 & 16 & 8 & 32 & 32 & 32 & 64 & 16 & 8 \\
\hline $\mathrm{C} 4$ & 16 & 8 & 32 & 32 & 8 & 16 & 4 & 4 \\
\hline L5 & 32 & 16 & 32 & 64 & 64 & 128 & 32 & 16 \\
\hline $\mathrm{C} 5$ & 32 & 16 & 32 & 64 & 16 & 16 & 8 & 8 \\
\hline L6 & 32 & 8 & 32 & 64 & 64 & 64 & 32 & 16 \\
\hline C6 & 32 & 8 & 64 & 64 & 16 & 8 & 8 & 8 \\
\hline L7 & 16 & 16 & 32 & 64 & 32 & 32 & 16 & 8 \\
\hline $\mathrm{C7}$ & 16 & 16 & 128 & 128 & 16 & 16 & 8 & 8 \\
\hline $\mathrm{L}_{\text {mean }} *$ & 20.6 & 13.7 & 32.0 & 54.9 & $73.1^{+}$ & $86.9^{\dagger}$ & $25.1^{\dagger}$ & $13.7^{\dagger}$ \\
\hline $\mathrm{C}_{\text {mean }} *$ & 13.7 & 10.9 & 59.4 & 77.7 & $16.0^{+}$ & $18.3^{\dagger}$ & $7.7^{+}$ & $10.3^{\dagger}$ \\
\hline$p$-value & 0.201 & 0.338 & 0.085 & 0.307 & 0.003 & 0.003 & 0.004 & 0.097 \\
\hline
\end{tabular}

* arithmetic mean of minimum biofilm inhibitory concentrations (MBIC) for linear (L) and cyclic (C) lipopeptides. $\dagger$ $p$-values for significant differences $(p<0.05)$.

In general, the cyclic lipopeptides tested in this study were mostly characterized by either higher or identical biofilm-inhibiting activities as that of their linear counterparts. However, few exceptions (against E. coli: C1, C3, C6, C7; P. aeruginosa: C1, C7; C. tropicalis: C1) have been found. After all, the test lipopeptides exhibited promising biofilm-inhibitory activity. With Candida strains, cyclic lipopeptides (mean MBIC 7.7-18.3 $\mu \mathrm{g} / \mathrm{mL}$ ) were more effective than the linear ones $(13.7-86.9 \mu \mathrm{g} / \mathrm{mL}$ ) ( $p$-value; 0.003-0.097). Overall, MBICs were below MBECs (even four-fold); however, with the linear lipopeptides, the MBIC values were equal to those of MBECs (L1, L3 against S. aureus, and L6, L7 against $C$. lipolytica). For these compounds, biofilm-inhibitory properties can be the result of anti-adhesive activity based on their interactions with the microbial surface, biomaterial surface or surrounding medium [51]. Such characteristics indicate how important taking into account the material of microtiter plates while planning the microbiological assays is. In this study, polystyrene (PS) untreated (unmodified) plates were used, because ionic interactions are seemingly one of the key factors of microbial adhesion [52]. Unmodified PS is hydrophobic, and its surface can be modified on account of hydrophobic interactions between biomaterial surface and the fatty acid chain. For instance, it is well documented that surface charge on PS (either negative or positive) significantly reduces $P$. aeruginosa adhesion [53]. This finding is consistent with those of the present study for as much as the positively charged lipopeptides dissolved in the medium reduced biofilm formation of those bacteria. Similarly, in our previous article on USCLs, the MBEC and MBIC values were usually higher than the determined MICs. Moreover, the biofilm formed on contact lenses was more resistant to USCLs than that formed on polystyrene [54]. Presumably, one of the mechanisms is based on competition between negatively charged surface of a material (contact lenses; methacrylic acid of etafilcon A) and negatively charged bacterial membrane (binding of the peptide to biomaterial) for positively charged USCLs. In effect, the number of USCLs that are able to effectively disrupt pathogenic cells is reduced $[55,56]$. To sum up, it can be stated that one of the key factors influencing biofilm resistance to USCLs is the type of material on which it is formed.

\subsection{MTT and Hemolysis Assay}

The results of hemolytic activity and cytotoxicity of lipopeptides and selectivity indexes (SI) are presented in Table 5. 
Table 5. Hemolytic activity (HC50) and cytotoxicity (IC50) to HaCaT and HeLa.

\begin{tabular}{|c|c|c|c|c|}
\hline Peptide Code & $\mathrm{HC}_{50}(\mu \mathrm{g} / \mathrm{mL})$ & HaCaT IC I0 $(\mu \mathrm{g} / \mathrm{mL})$ & $\operatorname{HeLa~IC}_{50}(\mu \mathrm{g} / \mathrm{mL})$ & SI (IC50 HaCaT/ IC50 HeLa) \\
\hline L1 & $90.0 \pm 6.5$ & $5.2 \pm 0.6$ & $3.9 \pm 1.1$ & 1.3 \\
\hline $\mathrm{C} 1$ & $43.9 \pm 3.5$ & $23.6 \pm 6.0$ & $25.5 \pm 2.9$ & 0.9 \\
\hline L2 & $105.9 \pm 8.0$ & $23.5 \pm 1.3$ & $12.8 \pm 1.1$ & 1.8 \\
\hline $\mathrm{C} 2$ & $30.6 \pm 1.1$ & $26.9 \pm 1.9$ & $17.9 \pm 2.1$ & 1.5 \\
\hline L3 & $79.1 \pm 6.1$ & $23.6 \pm 3.4$ & $8.4 \pm 1.7$ & 2.8 \\
\hline $\mathrm{C} 3$ & $66.5 \pm 14.8$ & $36.8 \pm 2.7$ & $38.8 \pm 4.4$ & 0.9 \\
\hline L4 & $79.8 \pm 9.0$ & $4.3 \pm 0.9$ & $3.0 \pm 0.6$ & 1.4 \\
\hline $\mathrm{C} 4$ & $122.4 \pm 16.5$ & $33.8 \pm 3.1$ & $27.5 \pm 3.4$ & 1.2 \\
\hline L5 & $96.7 \pm 1.4$ & $2.4 \pm 0.4$ & $6.2 \pm 2.7$ & 0.4 \\
\hline C5 & $97.0 \pm 15.4$ & $12.9 \pm 4.6$ & $21.9 \pm 4.5$ & 0.6 \\
\hline L6 & $89.7 \pm 2.4$ & $7.5 \pm 0.8$ & $3.6 \pm 0.5$ & 2.1 \\
\hline C6 & $71.0 \pm 6.4$ & $45.7 \pm 13.5$ & $30.4 \pm 2.5$ & 1.5 \\
\hline L7 & $65.4 \pm 1.5$ & $8.1 \pm 1.1$ & $3.0 \pm 0.4$ & 2.7 \\
\hline $\mathrm{C} 7$ & $92.0 \pm 9.6$ & $21.3 \pm 8.2$ & $20.9 \pm 2.1$ & 1.0 \\
\hline $\mathrm{L}_{\text {mean }} *$ & 86.7 & $10.7^{\dagger}$ & $5.8^{+}$ & 1.8 \\
\hline $\mathrm{C}_{\text {mean }}$ * & 74.7 & $28.7^{\dagger}$ & $26.1^{+}$ & 1.1 \\
\hline$p$-value & 0.375 & 0.013 & 0.00002 & 0.064 \\
\hline
\end{tabular}

${ }^{*}$ arithmetic mean of $\mathrm{HC}_{50} / \mathrm{IC}_{50} / \mathrm{SI}$ for linear (L) and cyclic (C) lipopeptides. SI-selectivity indexes; ${ }^{\dagger} p$-values for significant differences $(p<0.05)$.

The result of cytotoxicity assays revealed that all linear lipopeptides were more cytotoxic than their cyclic counterparts (HaCaT and HeLa). However, an identical hemolysis pattern is consistent only with peptides L4, C4, L7, and C7. A common feature of these compounds is the presence of arginine residue in the second and third position, which differentiates them from the rest of compounds used in this study. Overall effect of disulfide cyclization on hemolysis seems to be dependent on arginine(s) position. In general, disulfide cyclization of lipopeptides results in the reduced cytotoxicity and enhanced hemolysis (except C4 and C7). The differences in cytotoxicity against cell lines (HaCaT and HeLa) between groups of linear and cyclic lipopeptides are statistically significant $(p<0.05)$ in contrast to hemolysis. The toxicity of $\mathrm{C}_{16}-\mathrm{KKK}-\mathrm{NH}_{2}(\mathbf{L 1})$ against keratinocytes follows the same order of magnitude as already reported in the literature $(3.2 \mu \mathrm{g} / \mathrm{mL})$ [13]. It has been shown that antimicrobial activity and toxicity depend on peptide hydrophobicity and the net charge. Longer fatty acid chain leads to more active and toxic compounds, but there is an optimal chain length (hydrophobicity) required to effectively disrupt pathogenic membranes but keep the toxicity low [17,57].

In this study, hemolysis of linear (L1 and L2) and cyclic (C1 and C2) USCLs with lysine residues were comparable (Table 5 and Figure 3). Interestingly, all linear lipopeptides with net charge +4 and arginine residues were more hemolytic than the four-lysine linear counterpart (3). In contrast to cyclic lipopeptides, all lipopeptides with an arginine residue were less hemolytic than C2 (higher HC50 despite elevated hydrophobicity). There is a linear correlation between HC50 and hydrophobicity of linear USCLs with net charge $+4\left(R^{2}=0.89\right)$. Similarly, HC50 of cyclic USCLs with one arginine residue (net charge +4$)$ is linearly correlated with peptide hydrophobicity $\left(R^{2}=0.81\right)$. Cyclic lipopeptides with four lysine residues (C2) and two arginine residues (C7) do not follow the trend (Figure 3B). At the same time, the cyclic lipopeptide with two arginine residues (C7) exhibited unexpectedly low hemolysis especially when its highest hydrophobicity among cyclic lipopeptides with +4 net charge is taken into account. These results indicate that not only hydrophobicity, but also secondary structure, arginine position, and the number of arginine residues in cyclic lipopeptides are important for their hemolytic properties. Again, with linear lipopeptides and the highest hydrophobicity of compound L1, the relatively low hemolysis can be surprising. Considering the importance of peptide net charge for its biological activity, it can be presumed that low hemolysis of $\mathbf{L} \mathbf{1}$ is due to the presence of one 
basic amino acid residue less (net charge +3 ) than in compounds with net charge +4 . This finding is consistent with the literature where USCLs with greater positive charge were more toxic to human erythrocytes [17]. Similar reasoning refers to cyclic lipopeptides where compound C1 (net charge +3 ) is the most hydrophobic and exhibited lower hemolysis than the most hydrophilic cyclic lipopeptide (C2). In other studies, USCLs with an $\mathrm{N}$-terminal hexadecenoic acid residue and three or four ornithine residues $\left(\mathrm{C}_{16}\right.$-Orn-Orn-Orn- $\mathrm{NH}_{2}, \mathrm{C}_{16}$-Orn-Orn-Orn-Orn- $\left.\mathrm{NH}_{2}\right)$, having in the side chain one methylene group less than lysine, exhibited markedly lower hemolysis than lysine counterparts L1 and L2. At the same time their antimicrobial activity was comparable to those of L1 and L2 [58]. Indeed, exchange of lysine to ornithine can be expected to result in cyclic USCLs with elevated selectivity between hRBC and pathogens. Furthermore, all of the tested lipopeptides are substantially toxic to cancer cells-HeLa (3.0-38.8 $\mu \mathrm{g} / \mathrm{mL})$. Similar analysis of cytotoxicity (HaCaT and HeLa) of linear and cyclic USCLs vs. adjusted retention time was performed (Figures S1 and S2). Interestingly, cytotoxicity of compounds C2-C6 to HeLa cells decreases with increasing peptide hydrophobicity $\left(R^{2}=0.88\right)$. No other correlations were observed. To assess the distinction in activity against cancer and healthy cells, the selectivity index was calculated as $\mathrm{IC} 50_{\mathrm{HaCaT}} / \mathrm{IC} 50_{\mathrm{HeLa}}$ (Table 5). The highest selectivity indexes (2.8 and 2.7) were found for the linear lipopeptides with one or two arginine residues at first or first and second position (L3 and L7, respectively). In general, linear lipopeptides seem to be more cytotoxic to HeLa over normal cells of $\mathrm{HaCaT}$ than cyclic ones (mean $\mathrm{SI}_{\mathrm{HaCaT} / \mathrm{HeLa}}$ of $1.8 \mathrm{vs.} 1.1$; $p$-value 0.064). Moreover, selectivity of USCLs to pathogens (MIC) over human normal cells was estimated. Selectivity indexes were calculated as IC50 $\mathrm{HaCaT}_{\mathrm{MIC}}\left(\mathrm{SI}_{\mathrm{HaCaT}}\right)$ or HC50/MIC $\left(\mathrm{SI}_{\mathrm{hRBC}}\right)$. The values of SIs are attached as a Supplementary Materials (Table S1). In Table 6, arithmetic means of selectivity indexes in groups of linear and cyclic analogs are presented.

A

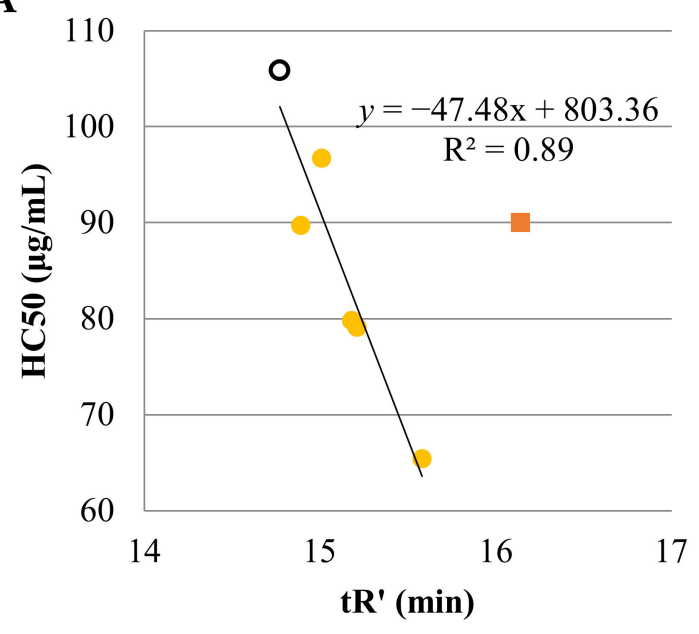

At least one Arg (+4) $\quad$ L1 (+3) OL2 (+4)
B

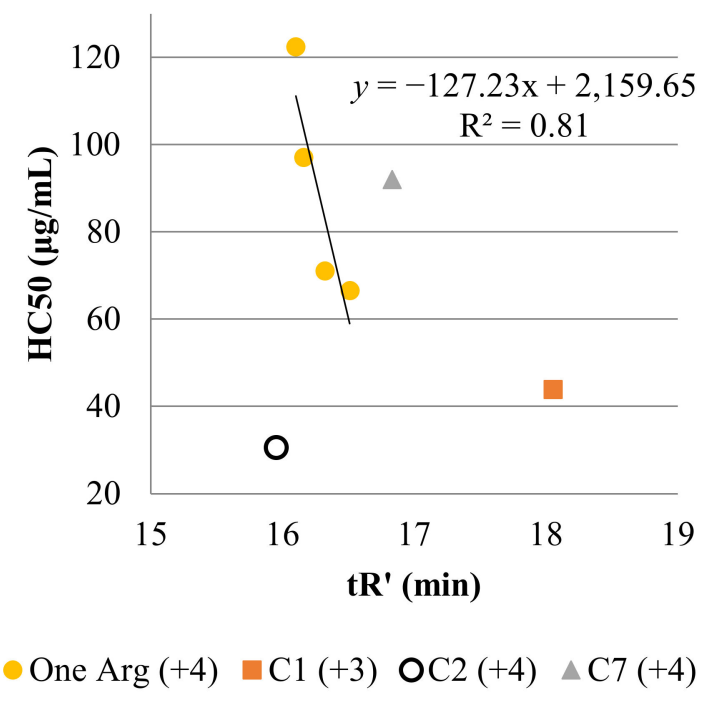

Figure 3. Hemolysis of-linear (A) and cyclic (B) USCLs vs. adjusted retention time. (A) At least one Arg (compounds L3, L4, L5, L6, L7)-linear correlation; (B) one Arg (compounds C3, C4, C5, C6)-linear correlation. 
Table 6. Analysis of selectivity indexes (left-linear, right-cyclic USCLs).

\begin{tabular}{|c|c|c|c|c|c|c|c|c|c|}
\hline \multicolumn{2}{|c|}{ Bacteria } & \multicolumn{2}{|c|}{ S. aureus } & \multicolumn{2}{|c|}{ S. epidermidis } & \multicolumn{2}{|c|}{ E. coli } & \multicolumn{2}{|c|}{ P. aeruginosa } \\
\hline \multirow{2}{*}{ hRBCs } & \multirow{2}{*}{$\begin{array}{c}\text { Mean } \\
p \text {-value }\end{array}$} & 6.17 & 8.52 & 13.60 & 13.51 & $8.61^{\dagger}$ & $3.60^{+}$ & $2.41^{\dagger}$ & $0.43^{\dagger}$ \\
\hline & & \multicolumn{2}{|c|}{0.2964} & \multicolumn{2}{|c|}{0.9777} & \multicolumn{2}{|c|}{0.0039} & \multicolumn{2}{|c|}{0.0022} \\
\hline \multirow{2}{*}{$\mathrm{HaCaT}$} & Mean & 1.37 & 2.04 & $1.61^{\dagger}$ & $4.62^{+}$ & 0.97 & 1.26 & 0.39 & 0.23 \\
\hline & $p$-value & \multicolumn{2}{|c|}{0.3452} & \multicolumn{2}{|c|}{0.0003} & \multicolumn{2}{|c|}{0.1600} & \multicolumn{2}{|c|}{0.7015} \\
\hline \multicolumn{2}{|c|}{ Fungi } & \multicolumn{2}{|c|}{ C. albicans } & \multicolumn{2}{|c|}{ C. glabrata } & \multicolumn{2}{|c|}{ C. lipolytica } & \multicolumn{2}{|c|}{ C. tropicalis } \\
\hline \multirow{2}{*}{ hRBCs } & Mean & $4.12^{\dagger}$ & $19.59^{+}$ & $2.17^{\dagger}$ & $15.77^{\dagger}$ & 20.00 & 35.44 & 17.00 & 29.07 \\
\hline & $p$-value & \multicolumn{2}{|c|}{0.0106} & \multicolumn{2}{|c|}{0.0022} & \multicolumn{2}{|c|}{0.0553} & \multicolumn{2}{|c|}{0.1599} \\
\hline \multirow{2}{*}{$\mathrm{HaCaT}$} & Mean & $0.67^{\dagger}$ & $8.36^{+}$ & $0.24^{\dagger}$ & $6.29^{+}$ & $1.82^{\dagger}$ & $13.39^{+}$ & $1.98^{+}$ & $12.29^{\dagger}$ \\
\hline & $p$-value & \multicolumn{2}{|c|}{0.0060} & \multicolumn{2}{|c|}{0.0022} & \multicolumn{2}{|c|}{0.0033} & \multicolumn{2}{|c|}{0.0049} \\
\hline
\end{tabular}

$+p$-values for significant differences $(p<0.05)$.

The highest $\mathrm{SI}_{\mathrm{hRBCs}}$ was recorded for cyclic lipopeptides and Candida sp. $(\mathrm{SI}=122.4)$. On the other hand, the lowest values were calculated for cyclic compounds and Gram-negative strains where hemolysis overweighed antimicrobial activity $(S I=0.1299)$. A similar spectrum of $S_{h R B C s}$ was observed for the linear and cyclic lipopeptides vs. Gram-positive bacteria (insignificant differences, Table 6). It is evident that cyclic molecules exhibited enhanced selectivity between fungi and HaCaT cell lines and between S. epidermidis and keratinocytes in contrast to those of linear counterparts. Considering antimicrobial activity against Gram-negative strains, the vast majority of compounds were nonselective. Those results are in agreement with the literature. It has been shown that cationic linear lipopeptides (net charge +2 and +3 ) with a hexadecanoic acid (C16) residue exhibited no selectivity between pathogens and keratinocytes (HaCaT) [13]. However, selectivity of USCL with four arginine (net charge +4 ) residues and hexadecanoic acid between hRBCs and bacteria/fungi based on previously determined activities is comparable to those estimated for linear USCLs used in this study [37]. In other studies, USCLs with arginine residues and shorter fatty acid chains (C14 and less) exhibited good selectivity between hRBCs, HaCaT cell line, and pathogens including bacterial strains and C. albicans $[8,14]$.

\subsection{Membrane Permeabilization}

Permeabilization of E. coli ML-35 membranes was studied to compare membrane disruption caused by linear lipopeptides and their cyclic analogs. USCLs selected for this study included (L2) $\mathrm{C}_{16}-\mathrm{KKKK}^{-\mathrm{NH}_{2}}$, (C2) $\mathrm{C}_{16}-\mathrm{CKKKKC}-\mathrm{NH}_{2}$ as reference lipopeptides and (C4) $\mathrm{C}_{16}-{\mathrm{CKRKKC}-\mathrm{NH}_{2}}_{2}$ and linear counterpart (L4), owing to high selectivity indexes of the cyclic lipopeptide (highest $\mathrm{SI}_{\mathrm{hRBCs}}=122.40, \mathrm{SI}_{\mathrm{HaCaT}}=33.80$, Table S1). The MICs against $E$. coli ML-35 of selected lipopeptides were determined (linear and cyclic lipopeptides, 4 and $8 \mu \mathrm{g} / \mathrm{mL}$, respectively). The outer membrane $(\mathrm{OM})$ and inner membrane (IM) permeabilization studies were performed at MIC (Figures 4 and 5, respectively). OM permeability studies are based on periplasmic $\beta$-lactamase action on CENTA to produce a yellow product. IM permeability studies are based on the action of cytoplasmic $\beta$-galactosidase on ONPG to produce chromophore ortho-nitrophenol (ONP). The $\beta$-galactosidase constitutive, lactose-permease deficient $E$. coli ML-35 strain was used. Accessibility of enzymes depends on OM and IM integrity. A PBS solution with ONPG/CENTA was used as a negative control.

In OM assay, cyclic and linear lipopeptides were similarly effective at both 4 and $8 \mu \mathrm{g} / \mathrm{mL}$ (Figure 4). However, permeabilization of IM was faster for C2 than for linear L2 at both concentrations (Figure 5; higher slope of a line). Similary C4 disrupts IM more rapidly than L4, however, only at $8 \mu \mathrm{g} / \mathrm{mL}$. USCLs achieved maximal absorbance (curve exhibiting plateau) in IM assay only at lower concentration $(4 \mu \mathrm{g} / \mathrm{mL})$ but no such effect was observed at $8 \mu \mathrm{g} / \mathrm{mL}$. Hypothetically, this can be due to self-assembly and formation of aggregates at higher concentrations that can reduce antimicrobial activity and affect interactions with membranes. IM permeabilization curves of $\mathbf{L} 4$ and $\mathbf{C} 4$ at $4 \mu \mathrm{g} / \mathrm{mL}$ (Figure 5C) achieved plateau at approximately 120 min, whereas for $\mathbf{L} 2$ and $\mathbf{C} 2$ at the same concentration (Figure 5A) it was 
spotted at approximately $90 \mathrm{~min}$. It seems that USCLs with an arginine residue (L4, C4) permeabilize IM a little slower than those lysine-based counterparts (L2, C2).

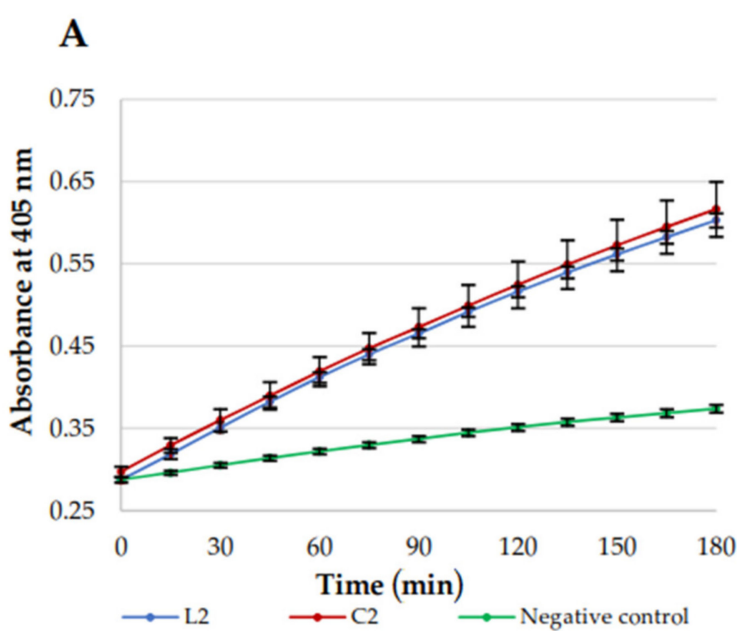

C

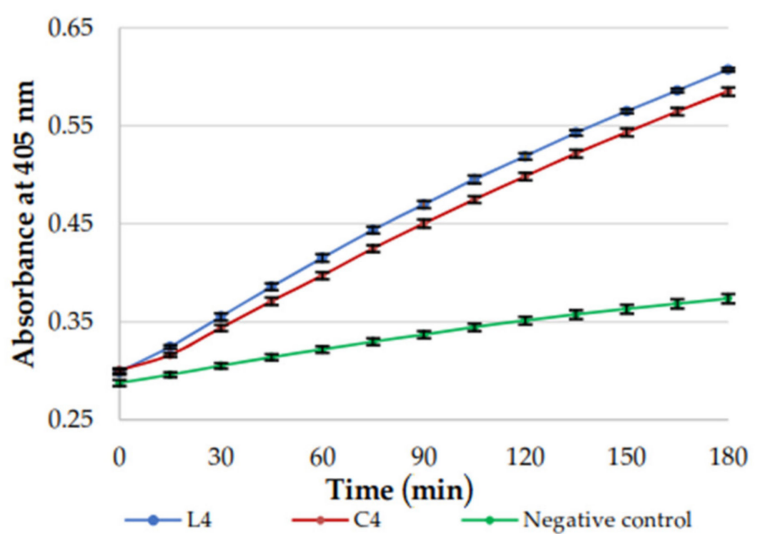

\section{B}

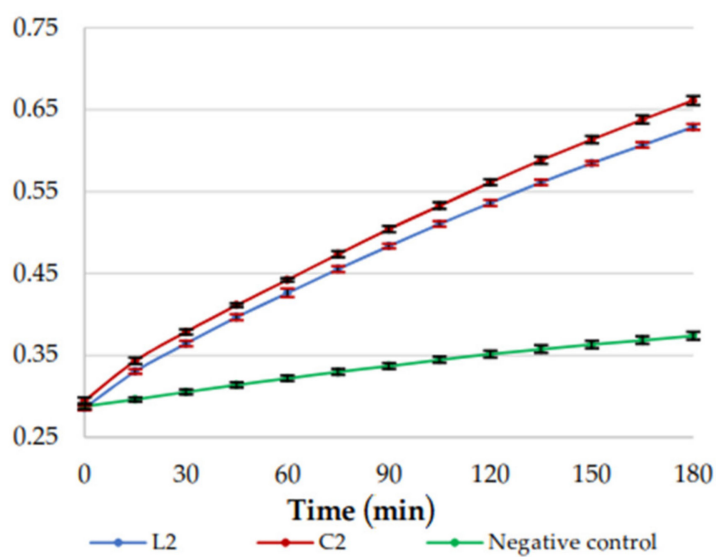

D

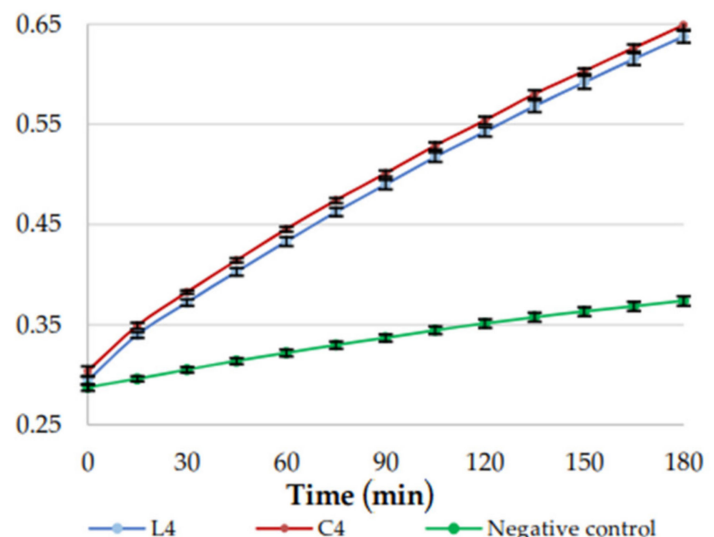

Figure 4. Outer membrane (OM) permeabilization kinetics. (A) L2 and C2, $4 \mu \mathrm{g} / \mathrm{mL}$; (B) L2 and C2, $8 \mu \mathrm{g} / \mathrm{mL}$; (C) L4 and C4, $4 \mu \mathrm{g} / \mathrm{mL}$; and (D) L4 and C4, $8 \mu \mathrm{g} / \mathrm{mL}$. 
A

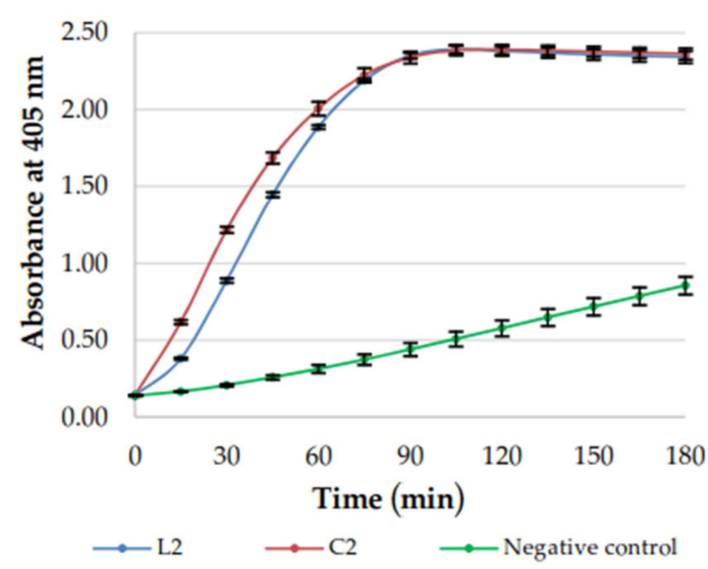

C

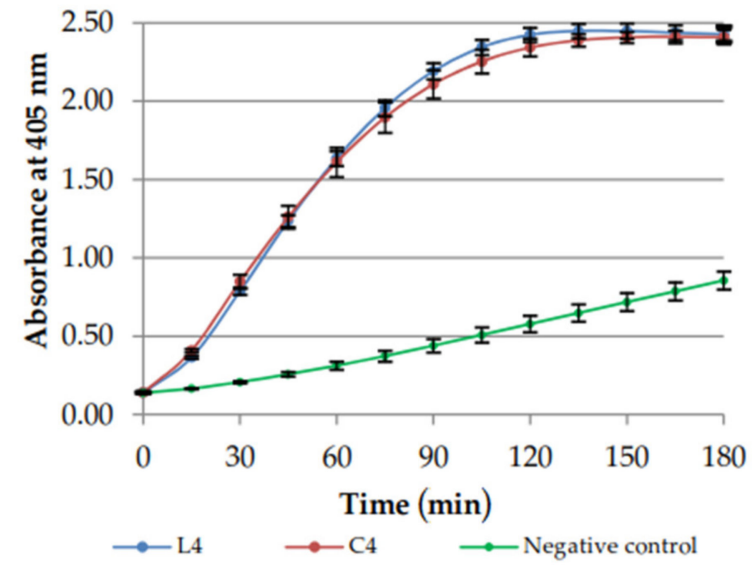

B

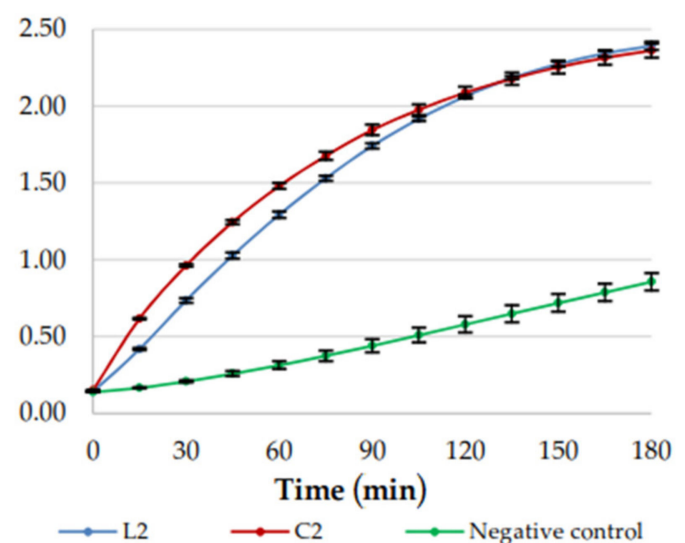

D

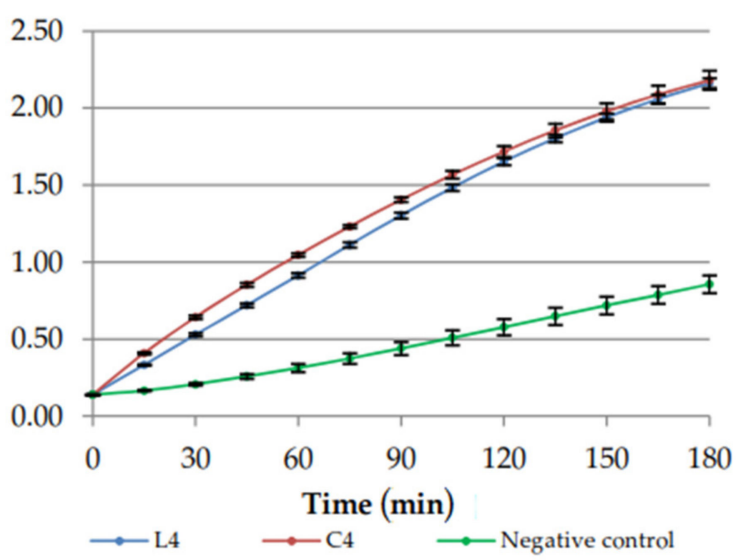

Figure 5. Inner membrane (IM) permeabilization kinetics. (A) L2 and C2, $4 \mu \mathrm{g} / \mathrm{mL}$; (B) L2 and C2, $8 \mu \mathrm{g} / \mathrm{mL}$; (C) L4 and C4, $4 \mu \mathrm{g} / \mathrm{mL}$; and (D) L4 and C4, $8 \mu \mathrm{g} / \mathrm{mL}$.

\subsection{Membrane Depolarization properties}

Membrane depolarization activities of selected lipopeptides (L2, C2, L4, C4) were evaluated using $\operatorname{DiSC}_{3}(5)$ membrane potential-depended dye. C. albicans, E. coli, and S. aureus were used in this assay. Results against $C$. albicans are presented in Figure 6, while for bacteria strains are attached as Supplementary Materials (Figures S3 and S4). Melittin was used as a popular membrane disrupting peptide [59]. The concentration of melittin was $64 \mu \mathrm{g} / \mathrm{mL}$.

A HEPES solution with glucose was used as a negative control. The released dye supports the hypothesis that the cell membrane is a target of synthesized lipopeptides. The results clearly indicate that the lipopeptides disrupt membranes of all pathogens used in this study. Lipopeptide $\mathrm{C}_{16}-\mathrm{KKKK}^{-N_{2}} \mathrm{H}_{2}$ (L2) and lipopeptides with arginine residues and hexadecanoic acid (C16) have been shown to interact with anionic lipid bilayers [16,60]. Depolarization of bacterial and fungal membranes (DiSC3(5)) was previously reported for cationic lipopeptides (net charge +4) [60]. 


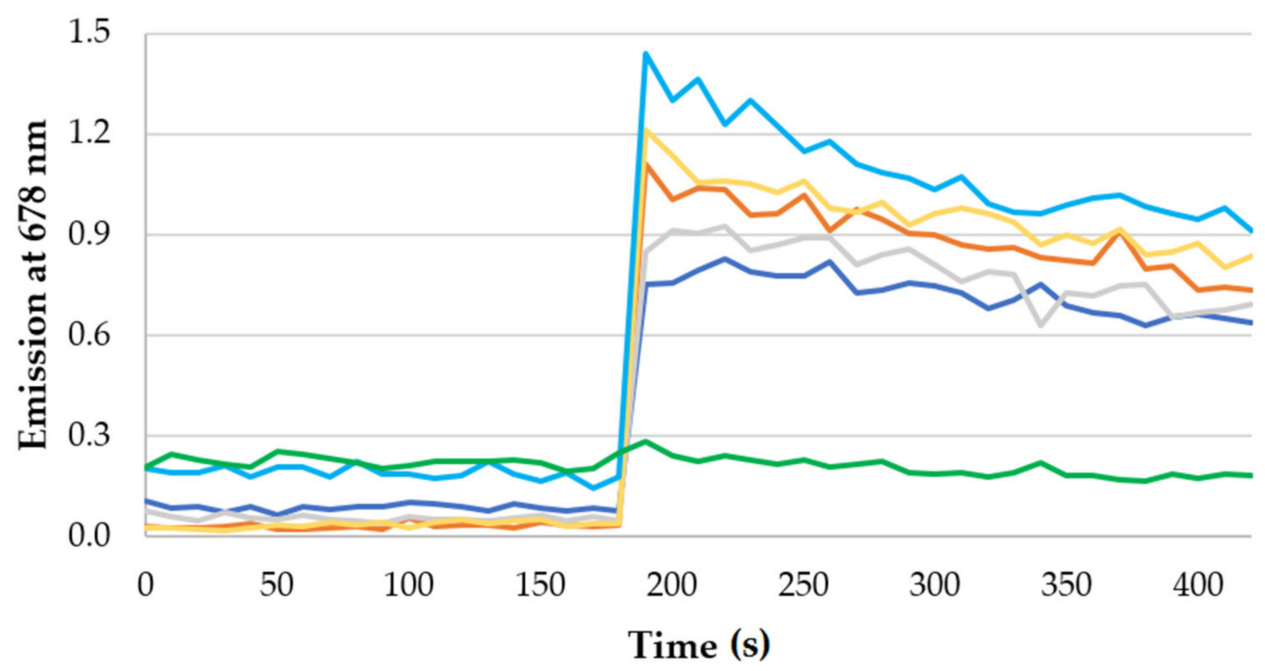

$-\mathrm{L} 2-\mathrm{C} 2-\mathrm{L} 4-\mathrm{C} 4-$ Melittin - Negative control

Figure 6. Results of fluorescence measurements of membrane potential-sensitive probe-C. albicans.

\subsection{Coarse-Grained Molecular Dynamics}

Coarse-grained molecular dynamics (CG MD) simulations were performed to visualize binding of the selected linear lipopeptides $\left(\mathbf{L} 2, \mathrm{C}_{16}-\mathrm{KKKK}^{-\mathrm{NH}_{2}} ; \mathbf{L} 4, \mathrm{C}_{16}-\mathrm{KRKK}^{-\mathrm{NH}_{2}}\right)$ and their cyclic counterparts $\left(\mathrm{C} 2, \mathrm{C}_{16}\right.$-CKKKKC-NH $\left.\mathrm{C}_{2} ; \mathrm{C} 4, \mathrm{C}_{16}-\mathrm{CKRKKC}-\mathrm{NH}_{2}\right)$ to bacterial and fungal membranes. The results showed that replacement of Lys by Arg had no significant effect on interactions of the lipopeptides with bacterial and fungal membranes in the coarse-grained model. In each system studied, two competitive processes were noticed, during the first nanoseconds of simulations, in other words, insertion of the lipopeptides into membrane matrix and self-assembly into micelles, which were attracted by the membrane surface in subsequent steps (Figure 7 and Figures S5, S7, and S9). Due to the periodic boundary conditions and crowding of the lipopeptide molecules in the initial steps of simulations, some of the molecules were free to bind with the inner leaflet of the membrane. They were removed from the system to mimic the physiological conditions, where the peptides attach only to the outer leaflet of the membrane and the simulations were continued with a reduced number of lipopeptide molecules and corrected counterions numbered. In the further steps, surface-bound lipopeptides micelles were either inserted and gradually dispersed within the outer leaflet of the membrane or remained attached to the membrane surface, with the other option being more representative of the fungal membrane. Nevertheless, even the surface-bound lipopeptide micelles affected the membrane through a distinct enrichment of POPG and POPI lipids at the binding site with the membrane surface resulting in POPG and POPI-rich domains in bacterial and fungal membrane, respectively (Figure 8 and Figures S6, S8, and S10). Formation of lipid domains resulted in nonuniform distribution of the lipids with different size headgroups and changed the local membrane thickness. The average thickness of both types of membranes is $\sim 39.5 \AA$, this being compatible with that of the previous study [61]. However, in the space directly beneath the attached lipopeptide micelles, a distinct reduction in the membrane thickness and local area per lipid (APL) was noticed. Interestingly, in the case of (C4) $\mathrm{C}_{16}-\mathrm{CKRKKC}-\mathrm{NH}_{2}$ bound to the fungal membrane (Figure $8 \mathrm{~B}$ ), a characteristic ring was formed at the binding site, in the middle of which the membrane was clearly thinner than on the outside. This indicated that $(\mathrm{C} 4) \mathrm{C}_{16}-\mathrm{CKRKKC}-\mathrm{NH}_{2}$ induced an extensive increase in membrane permeability, which is consistent with its impressive antifungal activity. 
A)
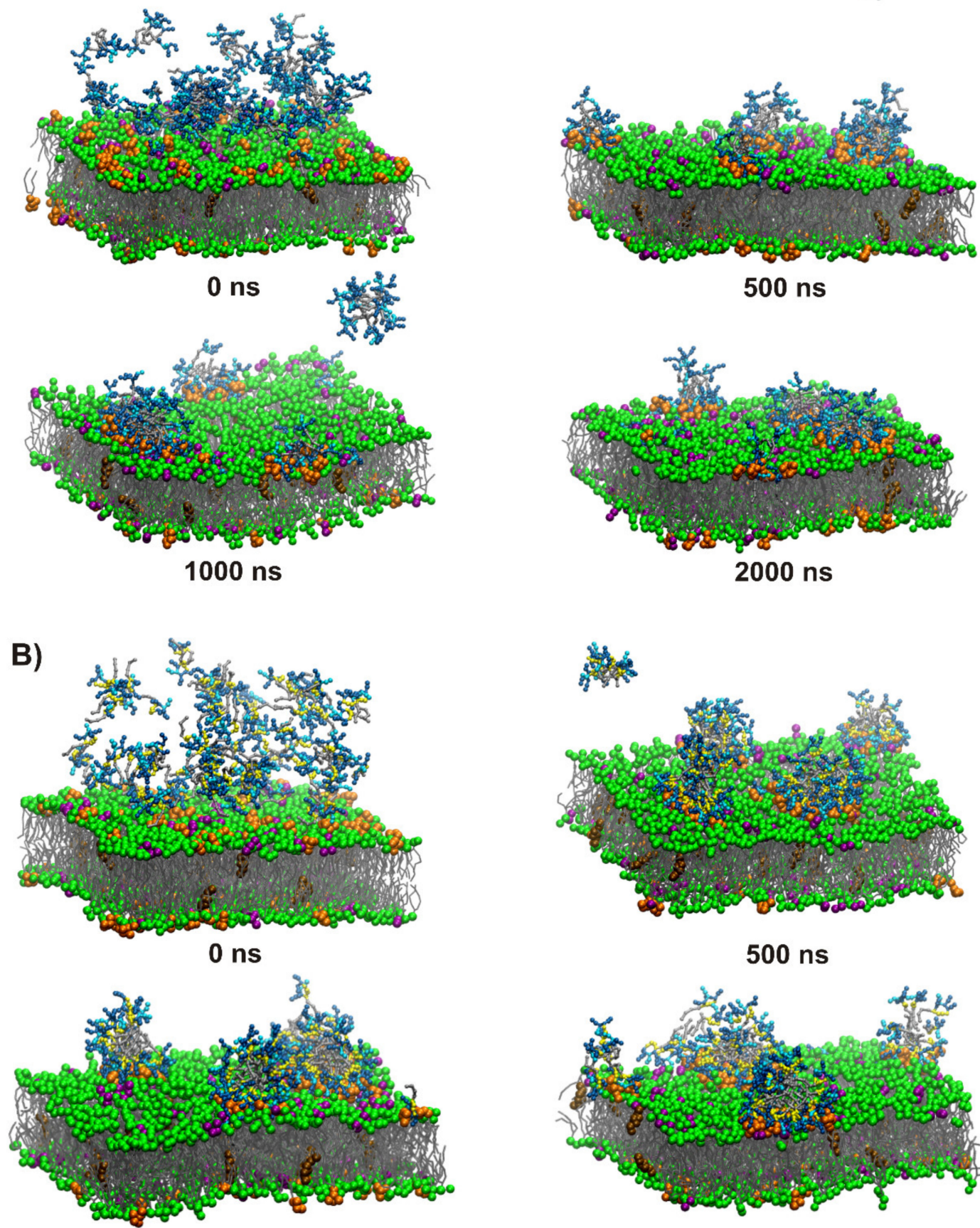

$1000 \mathrm{~ns}$

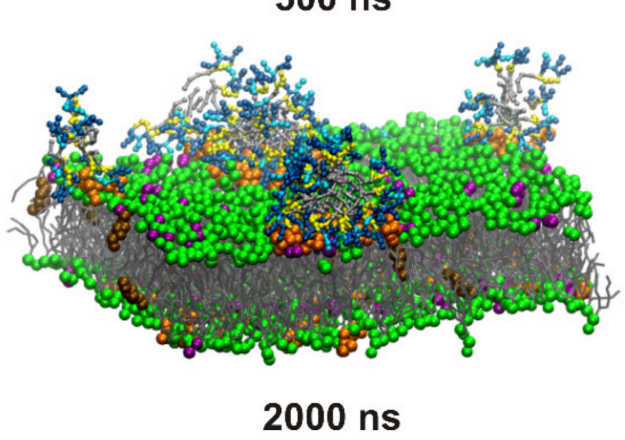

Figure 7. Snapshots from the POPC:POPE:POPS:POPI:ERGO (fungal membrane) binding simulations for $\mathrm{C}_{16}-\mathrm{KRKK}-\mathrm{NH}_{2}(\mathbf{A})$ and $\mathrm{C}_{16}-\mathrm{CKRKKC}-\mathrm{NH}_{2}$ (B). Fatty acid tails are colored silver, while lysines, arginines, and cysteines are blue, cyan, and yellow, respectively. Lipid tails are gray, while lipid head groups are purple for POPG, green for POPC and POPE, and orange for POPI. Ergosterol (brown) is immersed in the hydrophobic part of the membrane. 
A)

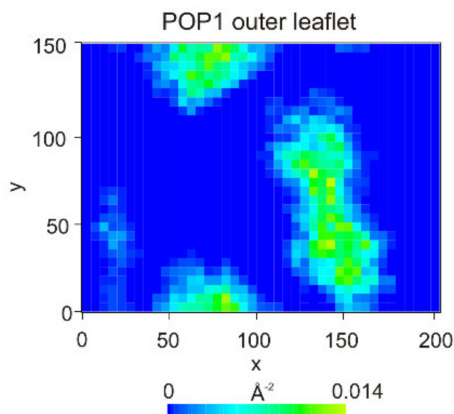

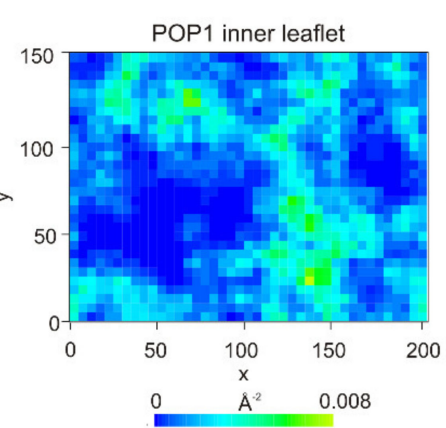

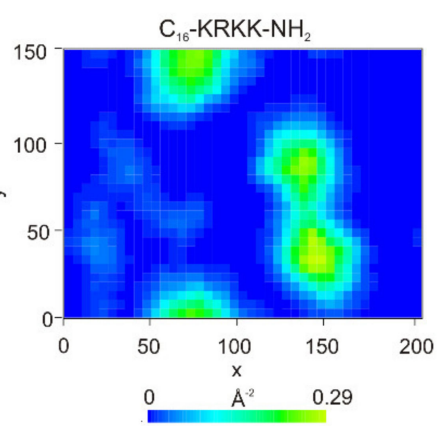

Thickness
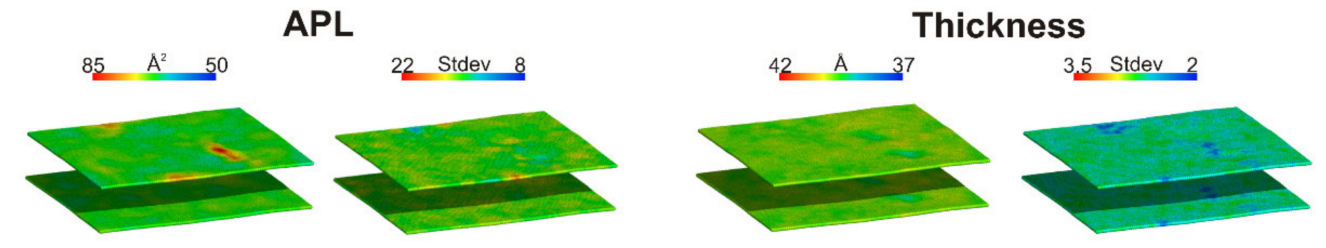

B)
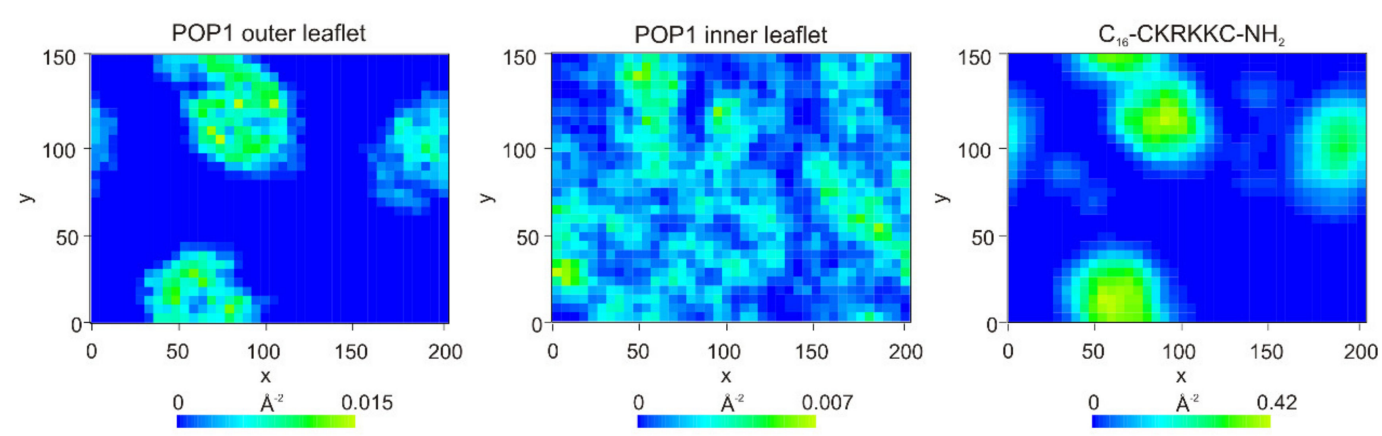

APL
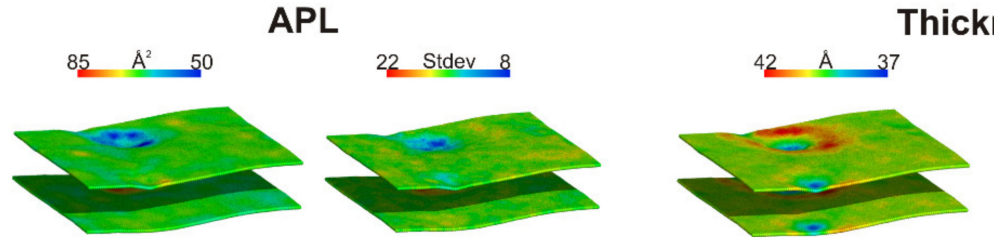

Thickness

Figure 8. 2D density map of the lipopeptides and POPI lipids in the outer and inner leaflets of the POPC:POPE:POPS:POPI:ERGO membrane (a grid spacing was set to $5 \AA$ ), local area per lipid (APL) and standard deviations of the local membrane area per lipid (APL) and local thickness of the bilayer and standard deviations of the local thickness of the bilayer averaged over the last $100 \mathrm{~ns}$ of a total of $2 \mu \mathrm{s} C \mathrm{G}$ $\mathrm{MD}$ (coarse-grained molecular dynamics) simulations of $\mathrm{C}_{16}-\mathrm{KRKK}^{-\mathrm{NH}_{2}}(\mathbf{A})$ and $\mathrm{C}_{16}-\mathrm{CKRKKC} \mathrm{NH}_{2}$

(B). Phosphate beads of the lipid headgroups were considered for calculations.

2.8. Visualization of Candida albicans Cells Treated with Selected Lipopeptides by Fluorescence Microscopy and Transmission Electron Microscopy

As the disulfide-cyclized lipopeptide analogs exhibited exceptionally high activity against Candida strains, fluorescence microscopy (FM) and transmission electron microscopy (TEM) were applied to visualize perturbations of Candida cells caused by selected lipopeptides (L2, C2, L4, C4). Melittin was used as a popular membrane disrupting peptide (positive control). Fluorescence microscopy images are displayed in Figure 9. Dyes used in this study were $N$-(3-triethylammoniumpropyl)-4-(4-(dibutylamino) styryl) pyridinium dibromide (FM 1-43) and propidium iodide (PI). 

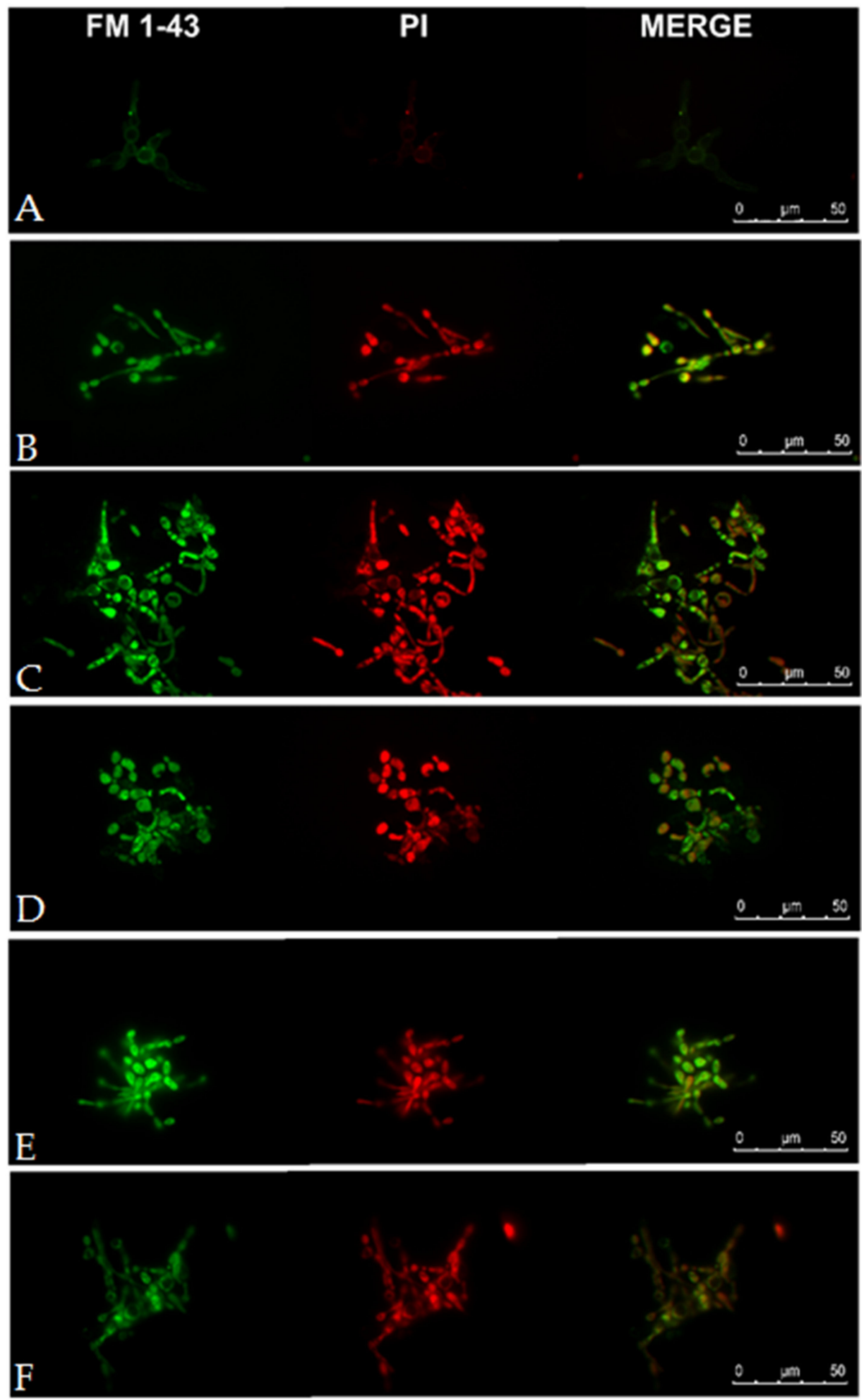

Figure 9. Fluorescence microscopy images of C. albicans ATCC 10231 cells. (A)-no additive, negative-control; (B)—melittin as positive control; (C) -lipopeptide L2; (D) 4-lipopeptide C2; (E)-lipopeptide L4; and (F)-lipopeptide C4.

FM 1-43 is an amphiphilic styryl green fluorescent dye that can be used to stain plasma membranes and organelle membranes in fungal cells [62]. PI needs to bind to double-stranded DNA to emit red fluorescence and cannot cross intact plasma membranes. Negative control reveals a faint green fluorescence of FM 1-43 integrated with plasma membrane and absence of red fluorescence (PI) inside 
the fungal cell. FM 1-43 dye can stain internal membranes, especially mitochondria ca. 30 min after dye addition [63]. Observations were made immediately after peptide addition to eliminate natural dye uptake (endocytosis). Lipopeptides, similar to melittin, permeabilize cell membranes facilitating dye penetration and binding with internal membranes (green fluorescence). Red fluorescence from PI confirmed permeabilization of cell membrane of yeast treated with both lipopeptides (L2, C2, L4, C4) and melittin.

Transmission electron microscopy images are presented in Figure 10.
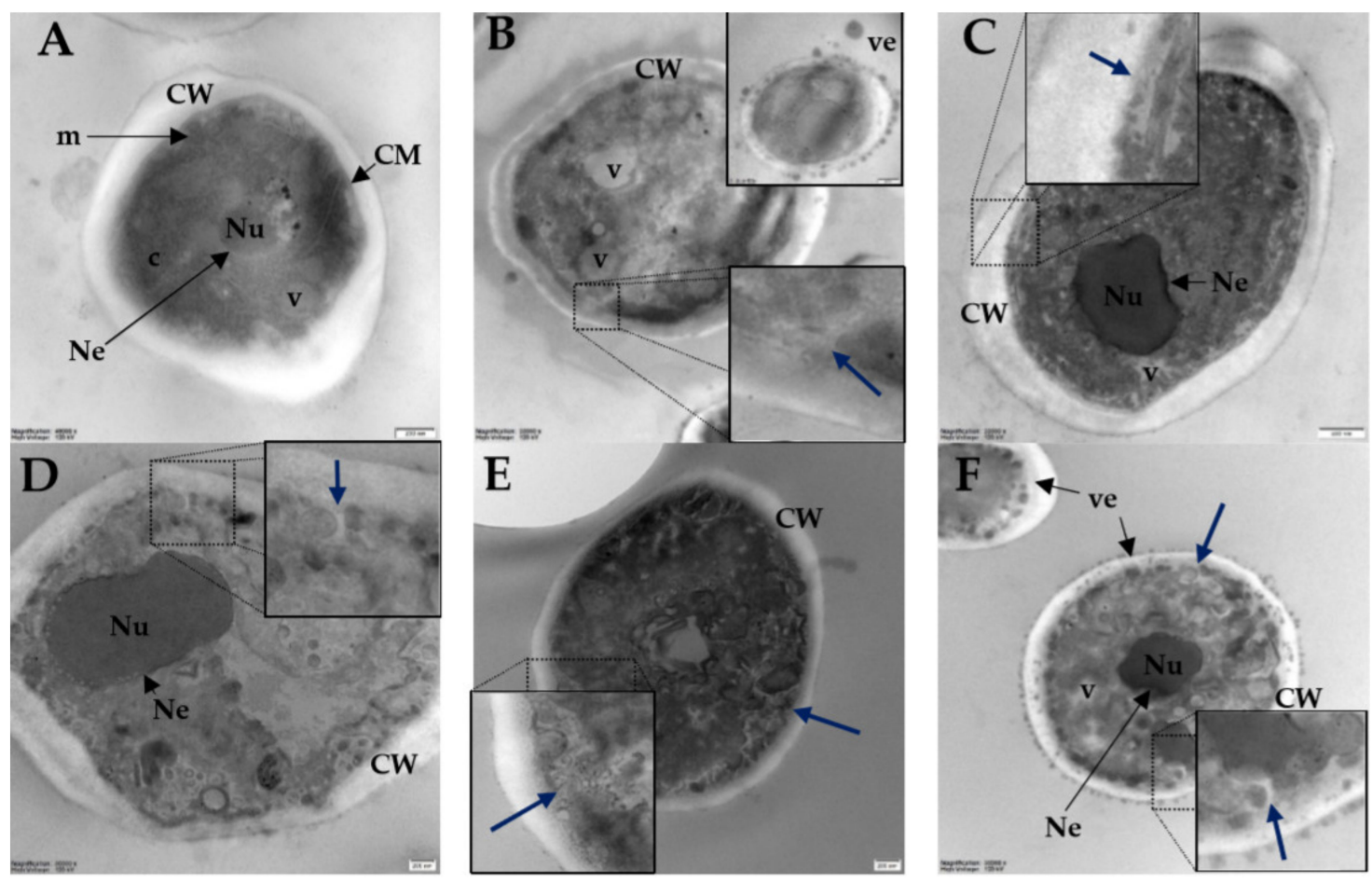

Figure 10. Transmission electron microscopy (TEM) images of C. albicans ATCC 10231 cells. (A)—no additive, negative-control; (B) - melittin as positive control; (C)—lipopeptide L2; (D) -lipopeptide C2; (E)-lipopeptide L4; and (F)-lipopeptide C4. CM-cell membrane, CW—cell wall, c-cytoplasm, $\mathrm{m}$-mitochondrion, $\mathrm{Nu}$-nucleus, $\mathrm{Ne}$-nuclear envelope, $\mathrm{v}$ - vacuole, ve-vesicles.

In TEM micrographs of untreated cells (Figure 10A) a typical morphology is seen. Normal cells have a regular thick cell wall, continuous cell membrane, a noticeable nucleus surrounded by intact nuclear envelope, and numerous vacuoles and mitochondria in the cytoplasm. Cells treated with melittin and lipopeptides have membranes detached from the cell wall with plasma membrane invaginations (blue arrows). Moreover, all compounds caused multiple small lobes of vacuoles. In the micrographs of cells treated with melittin and lipopeptide $\mathbf{C} 4$ numerous vesicles are visible inside and outside the cell. These bleb-like structures over the Candida albicans cells treated with melittin were seen previously using scanning electron microscopy [64]. Similar bleb-like structures occurred in Gram-negative bacteria treated with polymyxin B and colistin, cationic cyclic lipopeptide antibiotics $[65,66]$. Undoubtedly, all peptides caused disintegration of cytoplasm and organelles. None of the peptides caused damage to the cell wall. These results are consistent with a previous study on lipopeptides with lysine residues and palmitic acid attached to the $\mathrm{N}$-terminus, where damage to the membrane was reported $[40,67]$. 


\section{Materials and Methods}

\subsection{Peptide Synthesis}

Peptides were synthesized manually by solid-phase Fmoc/tBu methodology. Polystyrene resin modified by Rink Amide linker was used as the solid support. Deprotection of the Fmoc group was performed with a $20 \%(v / v)$ piperidine solution in DMF for $15 \mathrm{~min}$. Acylation was conducted with a mixture of DIC:OxymaPure:Fmoc-AA-OH (mole ratio 1:1:1) dissolved in DMF:DCM (1:1, v/v) in fourfold excess based on the resin for $1.5 \mathrm{~h}$. After deprotection and coupling reactions, the resin was rinsed with DMF and DCM and subsequently the chloranil test was carried out. The peptides were cleaved from the resin using one of the mixtures; (A) TFA, EDT, TIS, and water (92.5:2.5:2.5:2.5 $v / v / v / v)$; (B) TFA, TIS, and water (95:2.5:2.5 v/v/v). Mixture (A) was used with peptides containing a cysteine residue, whereas mixture (B) for the remaining peptides. Cleavage was accomplished within $1.5 \mathrm{~h}$ under stirring. Then the peptides were precipitated with cooled diethyl ether and lyophilized. The crude peptide with cysteine was dissolved in $20 \%(v / v)$ acetic acid solution $(0.5 \mathrm{~g} / \mathrm{L})$ and oxidized with iodine to obtain the peptide with intramolecular disulfide bridge. The peptides were purified by RP-HPLC. Pure fractions (>95\%, HPLC) were collected and lyophilized. The identity of all compounds was confirmed by mass spectrometry (ESI-MS). Melittin (GIGAVLKVLTTGLPALISWIKRKRQQ-NH ${ }_{2}$ ) used in this study was also synthesized on solid-support as first described. It was cleaved from the resin for $1.5 \mathrm{~h}$ using a TFA, TIS, phenol, and water (92.5:2.5:2.5:2.5, v/v/v/v) mixture.

\subsection{Determination of Peptide Hydrophobicity with RP-HPLC}

To determine peptide hydrophobicity, a Waters Alliance e2695 system with a Waters 2998 PDA Detector (software-Empower 3, Waters, Milford, MA, USA) was used. All analyses were carried out on a Waters X-Bridge Shield RP-18 column $(3.0 \times 100 \mathrm{~mm}, 3.5 \mu \mathrm{m}$ particle size, $130 \AA$ A pore size). The Shield Technology column with embedded polar groups was used to minimize interactions of unreacted silanol groups with basic lipopeptides [68]. The peptides were dissolved in water $(0.1 \%$ TFA, v/v) up to a concentration of $1 \mathrm{~g} / \mathrm{L}$. UV detection at $214 \mathrm{~nm}$ was used, and samples $(10 \mu \mathrm{L})$ were eluted with a linear $20-65 \%$ acetonitrile gradient in deionized water over $30 \mathrm{~min}$ at $25.0 \pm 0.1^{\circ} \mathrm{C}$. The mobile phase flow rate was $0.5 \mathrm{~mL} / \mathrm{min}$. Both eluents contained $0.1 \%(v / v)$ of TFA. Each peptide sample was analyzed in triplicate. Maximum standard deviation and coefficient of variation were 0.042 and $0.25 \%$, respectively.

\subsection{Antimicrobial Activity}

\subsubsection{Cultivation of Microorganisms}

The Staphylococcus aureus ATCC 25923, Staphylococcus epidermidis ATCC 14990, Escherichia coli ATCC 25922, Pseudomonas aeruginosa ATCC 9027, Candida albicans ATCC 10231, Candida glabrata ATCC 15126, Candida lipolytica PCM 2680-FY, and Candida tropicalis PCM 2709-FY strains were acquired from the Polish Collection of Microorganisms (PCM, Polish Academy of Sciences, Wrocław, Poland) and from the American Type Culture Collection (ATCC). All the strains were stored at $-80{ }^{\circ} \mathrm{C}$ in Roti-Store cryo vials and before the tests were transferred into fresh Mueller-Hinton broth (MHB, Biocorp, Warsaw, Poland) for bacteria or RPMI-1640 (Sigma-Aldrich, Steinheim, Germany) for fungi and incubated for $24 \mathrm{~h}$ at $37^{\circ} \mathrm{C}$. Then, the cultures were seeded on Mueller-Hinton agar (BioMaxima, Lublin, Poland) or Sabouraud dextrose agar (SDA, BioMaxima, Lublin, Poland) plates, respectively, and incubated as just mentioned. These agar cultures were used for further microbiological assays. Cell densities for all assays were adjusted spectrophotometrically (Multiskan GO Microplate Spectrophotometer, Thermo Fisher Scientific, Vantaa, Finland) at 600 and $660 \mathrm{~nm}$ for bacteria and fungi, respectively. 


\subsubsection{Activity against Planktonic Cultures}

The MICs were determined by broth microdilution method according to the Clinical and Laboratory Standard Institute guidelines $[69,70]$ For this purpose, initial inoculums of bacteria $\left(5 \times 10^{5} \mathrm{CFU} / \mathrm{mL}\right)$ in MHB and yeasts $\left(2 \times 10^{3} \mathrm{CFU} / \mathrm{mL}\right)$ in RPMI-1640 with $2 \%$ D-glucose were exposed to the ranging concentration of lipopeptides $(0.5-256 \mu \mathrm{g} / \mathrm{mL})$ and incubated at $37^{\circ} \mathrm{C}$ for $18 \mathrm{~h}$ and $24 \mathrm{~h}$, respectively. The experiments were conducted on 96-well microtiter polystyrene plates. The growth was assessed visually after incubation and the MIC was assumed as the lowest peptide concentration at which a noticeable growth of microorganisms was inhibited. All experiments were conducted in triplicate.

\subsubsection{Activity against Biofilm}

MBECs were determined on 96-well polystyrene flat-bottom plates. For this purpose, $24 \mathrm{~h}$ cultures of microorganisms were diluted to obtain final density $5.0 \times 10^{5} \mathrm{CFU} / \mathrm{mL}$ and $2.0 \times 10^{5} \mathrm{CFU} / \mathrm{mL}$ of bacteria and fungi, respectively. Briefly, $100 \mu \mathrm{L}$ of cell suspension was added into the test plates. After $24 \mathrm{~h}$ of incubation at $37^{\circ} \mathrm{C}$ the wells were rinsed three times with a phosphate buffer saline (PBS, $\mathrm{pH}$ 7.4) to remove non-adherent cells. Subsequently, $100 \mu \mathrm{L}$ of the test compounds in concentration range $(0.5-256 \mu \mathrm{g} / \mathrm{mL})$ were added to each well. After $24 \mathrm{~h}$ of incubation at $37^{\circ} \mathrm{C}, 20 \mu \mathrm{L}$ of a cell viability reagent was added (resazurin, $4 \mathrm{~g} / \mathrm{L}$; Sigma Aldrich, St. Louis, MO, USA). The MBEC was read after $1 \mathrm{~h}$. The determined values were recorded as the lowest concentration at which the reduction of resazurin (from blue to pink) was lower or equal to $10 \pm 0.5 \%$ as compared to the positive $(100 \%)$ and negative $(0 \%)$ controls. The reduction was monitored by measuring absorbance at $570 \mathrm{~nm}$ (reduced) and $600 \mathrm{~nm}$ (oxidized) using a microplate spectrophotometer (Multiskan GO Microplate Spectrophotometer, Thermo Fisher Scientific, Vantaa, Finland). All experiments were conducted in triplicate.

\subsubsection{Biofilm Inhibition Assay}

The assay was performed to evaluate the effect of the lipopeptides in preventing biofilm formation. The preparation of inoculums was followed by a ca. 500-fold dilution of the $24 \mathrm{~h}$ cultures of microorganisms. Briefly, $50 \mu \mathrm{L}$ of the compounds in the concentration range, diluted in appropriate medium, were prepared on 96-well polystyrene flat-bottom plates. Subsequently, the $50 \mu \mathrm{L}$ of the bacterial/fungal inoculums were added to reach the same microbial density as that in the MBEC assay. After $24 \mathrm{~h}$ of incubation at $37^{\circ} \mathrm{C}$, the wells were rinsed three times with PBS and the fresh media with resazurin $(4 \mathrm{~g} / \mathrm{L})$ were added. The MBICs were read after $1 \mathrm{~h}$. All experiments were conducted in triplicate.

\subsection{Permeabilization of E. coli ML-35 Membranes}

To assess lipopeptides ability to permeabilize inner (IM) and outer (OM) membranes of Gram-negative bacteria, the E. coli ML-35 (ATCC 43827) strain was used. The strain produces cytoplasmic $\beta$-galactosidase, periplasmic $\beta$-lactamase, and lacks lac permease. To examine OM permeabilization, CENTA was used as a $\beta$-lactamase substrate. In effect of OM permeabilization, the enzyme can hydrolyze CENTA's $\beta$-lactam ring. The resulting color change can be measured spectrophotometrically at $405 \mathrm{~nm}$ [71]. The IM permeabilization was monitored with ONPG, a chromogenic $\beta$-galactosidase substrate. The product of this reaction (4-nitrophenol) was measured spectrophotometrically at $405 \mathrm{~nm}$. Lipopeptide concentrations in OM and IM permeabilization assays were MIC ( $4 \mu \mathrm{g} / \mathrm{mL}$ of $\mathbf{L} \mathbf{2}$ and $\mathbf{L} 4$, and $8 \mu \mathrm{g} / \mathrm{mL}$ of $\mathbf{C} 2$ and $\mathbf{C 4})$. Bacteria were incubated in LB medium for $24 \mathrm{~h}$ at $37^{\circ} \mathrm{C}$. Subsequently, the cells were diluted in a fresh LB medium and incubated at $37^{\circ} \mathrm{C}$ up to a mid-log phase $(\mathrm{ca} .3 \mathrm{~h})$. The culture was centrifuged $(3 \mathrm{~min}, 1100 \times g)$ and rinsed twice with a PBS. The bacteria were resuspended in PBS up to a concentration of $5 \times 10^{6} \mathrm{CFU} / \mathrm{mL}$. The final concentration of ONPG and CENTA was $1.5 \mathrm{mM}$ and $0.15 \mathrm{mM}$, respectively. The ONPG/CENTA in PBS was used as negative control. Readings were taken every $15 \mathrm{~min}$ for $3 \mathrm{~h}$ at $37^{\circ} \mathrm{C}$ [72-75]. Experiments were performed in triplicate on 96-well microtiter polystyrene plates. 


\subsection{Membrane Depolarization Assay}

Depolarization of cell membranes was measured with 3,3'-dipropylthiacarbocyanine (diSC3(5)) as a probe. Membrane permeabilization could be assessed due to its depolarization and simultaneous release of the probe to the medium. Only the released dye can emit fluorescence to indicate membrane damage. S. aureus ATCC 25923, E. coli ATCC 25922, and C. albicans ATCC 10231, were grown at $37^{\circ} \mathrm{C}$ up to a mid-log phase (approx. $4 \mathrm{~h}$ ) in Mueller-Hinton (bacteria) or RPMI-1640 (fungi) broth. The cultures were centrifuged ( $3500 \mathrm{rpm}, 7 \mathrm{~min}$ ) and washed with $20 \mathrm{mM}$ glucose solution in HEPES buffer $(5 \mathrm{mM}$, $\mathrm{pH}$ 7.2). The cells were resuspended in $5 \mathrm{mM}$ HEPES buffer supplemented with $20 \mathrm{mM}$ glucose and $100 \mathrm{mM} \mathrm{KCl}$ (pH 7.2) to an OD 0.05 (OD600 and OD660 for bacteria and fungi, respectively). The final concentration of the dye was $0.4 \mu \mathrm{M}$. Fluorescence were monitored at $20^{\circ} \mathrm{C}\left(\lambda_{\mathrm{ex}} 620 \mathrm{~nm}\right.$ and $\lambda_{\mathrm{em}}$ $678 \mathrm{~nm}$ ) with Fluoroskan AscentFL (Thermo Fisher Scientific) fluorometer. As soon as the dye uptake attained a maximum the peptides were added at a concentration of $2 \times$ MIC. Melittin is known as an effective membrane disruptor, and as such it was used as a positive control $(2 \times \mathrm{MIC} ; 64 \mu \mathrm{g} / \mathrm{mL})$. A HEPES solution with glucose was used as a negative control. The measurements were run twice to ensure reproducibility.

\subsection{Hemolysis Assay}

The hemolysis assay was performed by using the method reported previously $[8,60]$. Fresh human red blood cells (hRBCs) with anticoagulant (EDTA) were rinsed three times with a PBS by centrifugation at $800 \times g$ for $10 \mathrm{~min}$ and diluted with PBS. The lipopeptides were serially diluted on a 96-well microtiter polystyrene plate and $\mathrm{hRBCs}$ were added up to a final volume of $100 \mu \mathrm{L}$. The peptide concentration ranged between 0.5 and $256 \mu \mathrm{g} / \mathrm{mL}$ and the final hRBCs concentration was $4 \%(v / v)$. Controls for zero hemolysis (blank) and 100\% hemolysis consisted of hRBCs suspended in PBS and 1\% of Triton-X 100, respectively. The plate was incubated for $1 \mathrm{~h}$ at $37^{\circ} \mathrm{C}$ and then centrifuged $\left(800 \times g, 10 \mathrm{~min}, 4^{\circ} \mathrm{C}\right)$. Subsequently, the supernatant was resuspended to new microtiter plates and the absorbance at $540 \mathrm{~nm}$ was measured. All experiments were conducted in triplicate. HC50 was calculated using an ic50.tk tool. Protocol of the study received approval from the local Bioethics Committee at the Medical University of Gdańsk (NKBBN/262/2019, approval date: 10 June 2019).

\subsection{MTT Assay}

To assess the cytotoxicity of the test lipopeptides (IC50), the classic MTT assay on 96-well polystyrene plates was performed for human keratinocytes (HaCaT) and human cervical adenocarcinoma cell line (HeLa S3) acquired from the ATCC. The assay utilizes colorimetric determination of the cell metabolic activity and the color intensity reflects the number of live cells that can be measured spectrophotometrically. The cell line was cultured in a Dulbecco's modified Eagle Medium (Invitrogen) supplemented with 10\% fetal bovine serum $(v / v), 100$ units $/ \mathrm{mL}$ of penicillin, $100 \mu \mathrm{g} / \mathrm{mL}$ of streptomycin, and $2 \mathrm{mM}$ l-glutamine and was stored at $37^{\circ} \mathrm{C}$ in a humidified $5 \% \mathrm{CO}_{2}$ incubator. Briefly, a day after plating of 500 cells per well, a series of concentrations $(0.1-200 \mu \mathrm{g} / \mathrm{mL})$ of the test compounds were applied. DMSO was added to the control cells at a final concentration of $1.0 \%$ $(v / v)$, which was related to the maximal concentration of the solvent compounds used in the experiment. After $24 \mathrm{~h}$ of incubation with the lipopeptides at $37^{\circ} \mathrm{C}$ in a humidified $5 \% \mathrm{CO}_{2}$ incubator, a medium containing $1 \mathrm{mg} / \mathrm{mL}$ of MTT (3-(4,5-dimethylthiazol-2-yl)-2,5-diphenyltetrazolium bromide) was added to the wells up to a final concentration of $0.5 \mathrm{mg} / \mathrm{mL}$. Subsequently, the plates were incubated at $37^{\circ} \mathrm{C}$ for $4 \mathrm{~h}$. Then, the medium was removed by suction, and the formazan product was solubilized with DMSO. The background absorbance at $630 \mathrm{~nm}$ was subtracted from that at $570 \mathrm{~nm}$ for each well (Epoch, BioTek Instruments, Winooski, VT, USA). Six replicates were conducted for each concentration. All experiments were repeated at least twice and the resulting IC50 values were calculated with a GraFit 7 software (v. 7.0, Erithacus, Berkley, CA, USA). 


\subsection{Fluorescence Microscopy}

Fungal cells (Candida albicans ATCC 10231) were incubated in RMPI-1640 overnight. The cells were then centrifuged ( $3500 \mathrm{rpm}, 7 \mathrm{~min}$ ) and resuspended in a fresh RMPI-1640 medium to obtain dense cell suspension $\left(0.5 \times 10^{7} \mathrm{CFU} / \mathrm{mL}\right)$. The cells were subsequently treated with USCLs and melittin at $2 \times$ MIC. Fungi were stained with $10 \mu \mathrm{M}$ FM 1-43 Dye (Thermo Fischer Scientific) and $2.5 \mu \mathrm{g} / \mathrm{mL}$ propidium iodide (PI, Sigma Aldrich) and immediately visualized using Nikon ECLIPSE E800 microscope with FITC and rhodamine filter (G-2A), respectively.

\subsection{Transmission Electron Microscopy (TEM)}

TEM was used to examine ultrastructural changes in the Candida albicans ATCC 10231 cells treated with selected lipopeptides (L2, C2, L4, C4) and melittin (positive control). Fungal cells (Candida albicans ATCC 10231) were incubated in RMPI-1640 overnight. The cells were centrifuged ( $3500 \mathrm{rpm}, 7 \mathrm{~min}$ ) and resuspended in fresh RMPI-1640 medium to obtain dense cell suspension $\left(5.0 \times 10^{6} \mathrm{CFU} / \mathrm{mL}\right)$. The high cell-density culture was prepared to facilitate TEM observations. Peptides' concentrations were $2 \times$ MIC. Samples were incubated for $1 \mathrm{~h}$ at room temperature. Importantly, MIC of selected peptides ( $\mathbf{2} 2, \mathbf{C 2}, \mathbf{L 4}, \mathbf{C 4}$, and melittin) were also determined with dense inoculum of yeasts $\left(5.0 \times 10^{6} \mathrm{CFU} / \mathrm{mL}\right)$. After the treatment, the fungal cells were centrifuged (3500× rpm, $10 \mathrm{~min})$ and washed twice with PBS. Fungal cells were fixed with $2.5 \%$ glutaraldehyde buffered at $\mathrm{pH} 6.5$ with $0.1 \mathrm{M}$ sodium cacodylate (Polysciences, Warrington, PA, USA) for $6 \mathrm{~h}$ at room temperature. Postfixation was performed with a $1 \%$ osmium tetroxide (Polysciences, Warrington, PA, USA) solution for $2 \mathrm{~h}$ at $4{ }^{\circ} \mathrm{C}$. The cells were then centrifuged and resuspended in $0.1 \mathrm{M}$ cacodylate buffer ( $\mathrm{pH}$ 6.5). After re-centrifugation, cells were dehydrated with ethanol. Yeasts were embedded in Epon 812 resin (Sigma-Aldrich) at room temperature. An ultramicrotome Leica UC7 was used to prepare ultrathin sections $(55 \mathrm{~nm})$. Lead citrate and uranyl acetate were added as contrasting agents. The cells were visualized using a Tecnai Spirit BioTWIN microscope (FEI) at $120 \mathrm{kV}$.

\subsection{Molecular Dynamics Simulations}

Simulations were carried out in the MARTINI coarse-grained force field [76,77] implemented in the GROMACS 4.6.3 package [78]. The model of fungal membrane was built from 958 lipids consisting of 485 POPC, 288 POPE, 94 POPS, and 94 POPI (mole ratio 5:3:1:1) equally distributed between both leaflets. Additionally, the fungal membrane included $2 \%$ of ergosterol (11 molecules per each leaflet) [61]. In turn, the bacterial membrane was built from 986 lipids consisting of POPG and POPE lipids at a mole ratio of 3:1, which mimicked the Gram-positive bacterial membrane [79]. Each system was constructed using an insane.py script available on the martini website (http://cgmartini.nl/cgmartini/). One hundred molecules of each lipopeptide were placed randomly on one leaflet of the membrane. The lipid to lipopeptide ratio was ca. 10:1. The entire system was solvated and neutralized by sodium and chloride ions to keep the concentration of the free salt ions at ca. $100 \mathrm{mM}$. Simulations of lipopeptide-membrane interactions were carried out in an isothermal-isobaric (NPT) ensemble with semi-isotropic pressure of $1 \mathrm{bar}$ and at a fixed temperature of $303 \mathrm{~K}$. The CG MD simulations for each system were run for $2 \mu \mathrm{s}$. The time step of $10 \mathrm{fs}$, as suggested by Winger et al. [80], was employed during the entire NPT simulations. The temperature was held at $303 \mathrm{~K}$ using the Nosé-Hoover temperature coupling. The pressure was treated semi-isotropically at 1 bar using the Parinello-Rahman barostat with a coupling constant $\tau_{p}=12 \mathrm{ps}$ and an isothermal compressibility of $4.5 \times 10^{-5} \mathrm{bar}^{-1}$. The relative dielectric constant for explicit screening was 15 . Electrostatics were computed with a shift function with a coulomb cutoff of $12 \AA$. The shift function was used for van der Waals interactions as well, with a switch distance of $9 \AA$ and a cutoff of $12 \AA$. The neighbor list was updated every 20 steps using a cutoff $14 \AA$ A. MD trajectory analysis was performed with the utilities included in the GROMACS package. Area per lipid (APL) was calculated using the GROMACS compatible analysis tool g_lomepro [81]. Visualizations were created with VMD [82]. 


\subsection{Statistical Analysis}

The results of antimicrobial activity (MIC, MBEC, MBIC) and cytotoxicity (HC50, IC50) studies were analyzed statistically. The peptides were divided into two equinumerous groups $(n=7)$ of linear and cyclic lipopeptides. A Shapiro-Wilk test was performed to evaluate normality in each group. When the data were normally distributed, a Levene's test was performed to study homogeneity of variance. Differences between groups were tested by either Student's $t$-test or Mann-Whitney U test. The Student's $t$-test was used when data were normally distributed, and variances were homogenous. If not, the Mann-Whitney $U$ test was used. The significance level $(\alpha)$ was 0.05 . The analyses were performed with TIBCO Statistica 13.3.0.

\section{Conclusions}

In this article, in vitro biological activities of $\mathrm{N}$-palmitoylated linear and cyclic lipopeptides were studied. All of the cyclic lipopeptides had a substantially high antimicrobial activity (MIC, MBEC) against Candida strains and low cytotoxicity against keratinocytes (HaCaT) in comparison with their linear counterparts. Generally, cyclic lipopeptides caused higher hemolysis (HC50) than did their parent molecules, but with a few exceptions. Furthermore, substitution of lysine with arginine led to analogs with a lower hemolytic activity but only in the case of cyclic lipopeptides. The most selective compound was a cyclic lipopeptide with one arginine and three lysine residues, (C4) $\mathrm{C}_{16}$-CKRKKC-NH 2 . Compounds used in this study exhibited distinct biofilm-inhibitory properties promoting them as candidates applicable in biomaterials and polymers. It has been shown that USCLs can be promising anti-biofilm and antimicrobial coatings and components of formulations with biodegradable polymers [50,83]. All in all, short cationic lipopeptides are molecules with high antimicrobial activity. Unfortunately a noticeable toxicity against human cells is a common feature of this class of compounds. In order to overcome this drawback, lipopeptides' polar head could be simply cyclized through disulfide formation. Moreover, this approach can lead to compounds with improved antimicrobial activity and selectivity between Candida strains and human cells. Further studies should include analysis of the hydrophobic fragment of the presented cyclic lipopeptides. Shortening of the fatty acid chain and addition of hydrophobic $N$-terminal amino acid residue can result in more active and selective compounds [8]. Furthermore, stability to enzymatic degradation should be considered especially with respect to the disulfide bridge that can be reduced or eventually (re)oxidized or conjugated to another sulfhydryl. A number of chemical strategies can be applied to overcome this drawback, for example, thioether bond or amide bond formation, with lipidation of the $N$-terminus, side-chain amino or hydroxyl group or even cysteine, in other words, through CLipPA chemistry using a fatty acid vinyl ester [84-86]. Another aspect that can be crucial to antimicrobial activity of cyclic ultrashort cationic lipopeptides is ring size. It was found that the ring size of cyclized antimicrobial peptides and lipopeptides (polymyxin B, echinocandins) was an essential factor that can affect biological activity [87-90].

Supplementary Materials: Supplementary materials can be found at http:/www.mdpi.com/1422-0067/21/19/ 7208/s1. The following are available online, Figure S1: Cytotoxicity of linear (A) and cyclic (B) USCLs to HaCaT vs. adjusted retention time; Figure S2: Cytotoxicity of linear (A) and cyclic (B) USCLs to HeLa vs. adjusted retention time; Figure S3: Results of fluorescence measurements of membrane potential-sensitive probe E. coli; Figure S4: Results of fluorescence measurements of membrane potential-sensitive probe S. aureus; Figure S5: Snapshots from the POPG:POPE (Gram-positive bacterial membrane) binding simulations for $\mathrm{C}_{16}-\mathrm{KKKK}^{\mathrm{N}} \mathrm{NH}_{2}$ (A) and $\mathrm{C}_{16}-\mathrm{CKKKKC}-\mathrm{NH}_{2}$ (B); Figure S4: 2D density map of the lipopeptides and POPG lipids in the outer and inner leaflets of the POPG:POPE membrane (a grid spacing was set to $5 \AA$ ), local area per lipid (APL) and standard deviations of the local membrane APL and local thickness of the bilayer averaged over the last $100 \mathrm{~ns}$ of a total of $2 \mu \mathrm{s}$ CG MD simulations of $\mathrm{C}_{16}-\mathrm{KKKK}-\mathrm{NH}_{2}$ (A) and $\mathrm{C}_{16}-\mathrm{CKKKKC}-\mathrm{NH}_{2}$ (B); Figure S7: Snapshots from the POPC:POPE:POPS:POPI:ERGO (fungal membrane) binding simulations for $\mathrm{C}_{16}-\mathrm{KKKK}^{-\mathrm{NH}_{2}}(\mathrm{~A})$ and $\mathrm{C}_{16}-\mathrm{CKKKKC}-\mathrm{NH}_{2}$ (B); Figure S8: 2D density map of the lipopeptides and POPI lipids in the outer and inner leaflets of the POPC:POPE:POPS:POPI:ERGO membrane (a grid spacing was set to $5 \AA$ ), local area per lipid (APL) and standard deviations of the local membrane APL and local thickness of the bilayer averaged over the last $100 \mathrm{~ns}$ of a total of $2 \mu \mathrm{s}$ CG MD simulations of $\mathrm{C}_{16}-\mathrm{KKKK}^{-\mathrm{NH}_{2}}$ (A) and $\mathrm{C}_{16}-\mathrm{CKKKKC}^{-\mathrm{NH}_{2}}$ (B); Figure S9: 
Snapshots from the POPG:POPE (Gram-positive bacterial membrane) binding simulations for $\mathrm{C}_{16}-\mathrm{KRKK}^{-\mathrm{NH}_{2}}$ (A) and $\mathrm{C}_{16}-\mathrm{CKRKKC}-\mathrm{NH}_{2}$ (B); Figure S10: 2D density map of the lipopeptides and POPG lipids in the outer and inner leaflets of the POPG:POPE membrane (a grid spacing was set to $5 \AA$ ), local area per lipid (APL) and standard deviations of the local membrane APL and local thickness of the bilayer averaged over the last $100 \mathrm{~ns}$ of a total of $2 \mu \mathrm{s}$ CG MD simulations of $\mathrm{C}_{16}-\mathrm{KRKK}-\mathrm{NH}_{2}(\mathrm{~A})$ and $\mathrm{C}_{16}-\mathrm{CKRKKC- \textrm {NH } _ { 2 }}$ (B); Table S1: The SI of the tested compounds.

Author Contributions: Conceptualization, D.N. and W.K.; methodology, D.N., E.S., M.B., M.J., M.K., M.N., and S.B.; validation, D.N., M.B., M.J., and S.B.; formal analysis, D.N.; investigation, D.N., E.S., M.B., M.J., M.K., M.N., and S.B.; resources, D.N. and W.K.; writing-original draft preparation, D.N.; writing—review and editing, D.N.; visualization, D.N., E.S., and M.K.; project administration, D.N.; funding acquisition, D.N. All authors have read and agreed to the published version of the manuscript.

Funding: This study was supported by the Polish Ministry of Science and Higher Education Grant for Young Investigators, No. 01-0305/08/508 (Funding approval date: 2 June 2017). Publication of the article was supported by the project POWR.03.02.00-00-I026/17-00 co-financed by the European Union through the European Social Fund under the Operational Programme Knowledge Education Development 2014-2020.

Acknowledgments: We wish to thank Ryszard Piękoś for his invaluable help in preparing the manuscript, and Adrian Zubrzycki for his help in analysis of TEM results.

Conflicts of Interest: The authors declare no conflict of interest. The funders had no role in the design of the study; in the collection, analyses, or interpretation of data; in the writing of the manuscript, or in the decision to publish the results.

\section{Abbreviations}

\begin{tabular}{|c|c|}
\hline BSA & Bovine serum albumin \\
\hline CENTA & 7-(thienyl-2-acetamido)-3-[(4-nitro-3-carboxyphenyl)thiomethyl]-3-cephem-4 carboxylic acid \\
\hline CFU & Colony forming units \\
\hline DCM & Dichloromethane \\
\hline DIC & $N, N^{\prime}$-diisopropylcarbodiimide \\
\hline DiSC3(5) & 3,3'-dipropylthiacarbocyanine iodide \\
\hline DMF & $N, N$-dimethylformamide \\
\hline DMSO & Dimethyl sulfoxide \\
\hline EDT & 1,2-ethaneditiol \\
\hline EDTA & Ethylenediaminetetraacetic acid \\
\hline ESI-MS & Electrospray ionization mass spectrometry \\
\hline FM 1-43 & $N$-(3-triethylammoniumpropyl)-4-(4-(dibutylamino) styryl) pyridinium dibromide \\
\hline Fmoc & Fluorenylmethoxycarbonyl \\
\hline $\mathrm{HaCaT}$ & Human keratinocytes \\
\hline $\mathrm{HC} 50$ & Peptide concentration causing $50 \%$ hemolysis \\
\hline HeLa & Human cervical adenocarcinoma cell line \\
\hline hRBCs & Human red blood cells \\
\hline IC50 & Peptide concentration causing $50 \%$ inhibition of the growth \\
\hline IM & Inner membrane \\
\hline LB & Luria-Bertani medium \\
\hline MBEC & Minimum biofilm eradication concentration \\
\hline MBIC & Minimum biofilm inhibitory concentration \\
\hline MHA & Mueller-Hinton agar \\
\hline MHB & Mueller-Hinton broth \\
\hline MIC & Minimum inhibitory concentration \\
\hline MTT & 3-(4,5-dimethylthiazol-2-yl)-2,5-diphenyltetrazolium bromide \\
\hline ONPG & o-nitrophenyl- $\beta$-D-galactopyranoside \\
\hline $\mathrm{OM}$ & Outer membrane \\
\hline Pal & Palmitic acid (hexadecenoic acid) \\
\hline PI & Propidium iodide \\
\hline POPC & 1-palmitoyl-2-oleoyl-sn-glycero-3-phosphocholine \\
\hline POPE & 1-palmitoyl-2-oleoyl-sn-glycero-3-phosphoethanolamine \\
\hline
\end{tabular}




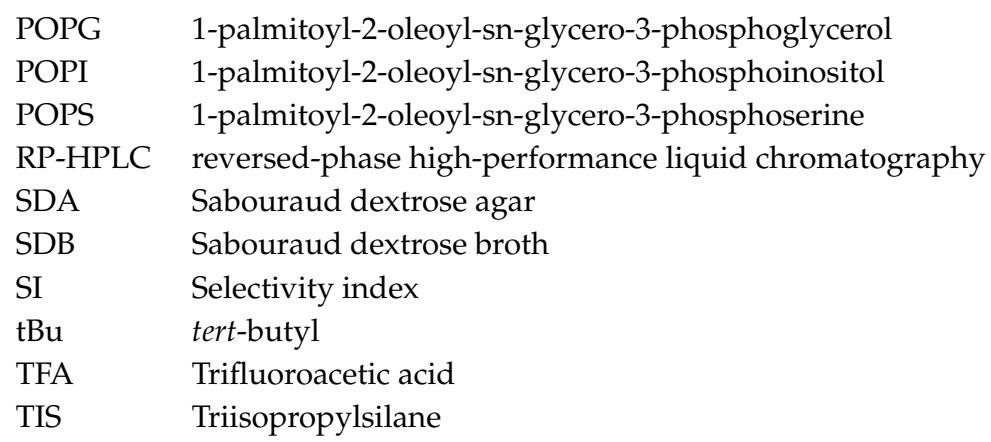

\section{References}

1. Venter, H.; Henningsen, M.L.; Begg, S.L. Antimicrobial resistance in healthcare, agriculture and the environment: The biochemistry behind the headlines. Essays Biochem. 2017, 61, 1-10. [CrossRef] [PubMed]

2. Błażewicz, I.; Jaśkiewicz, M.; Piechowicz, L.; Neubauer, D.; Nowicki, R.; Kamysz, W.; Barańska-Rybak, W. Increasing rate of daptomycin non-susceptible strains of Staphylococcus aureus in patients with atopic dermatitis. Adv. Dermatol. Allergol. 2017, 34, 547-552. [CrossRef] [PubMed]

3. Arendrup, M.C.; Perlin, D.S. Echinocandin resistance: An emerging clinical problem? Curr. Opin. Infect. Dis. 2014, 27, 484-492. [CrossRef]

4. Srinivas, P.; Rivard, K. Polymyxin Resistance in Gram-negative Pathogens. Curr. Infect. Dis. Rep. 2017, 19, 38. [CrossRef] [PubMed]

5. Makovitzki, A.; Avrahami, D.; Shai, Y.; Sela, M. Ultrashort antibacterial and antifungal lipopeptides. Proc. Natl. Acad. Sci. USA 2006, 103, 15997-16002. [CrossRef] [PubMed]

6. Jerala, R. Synthetic lipopeptides: A novel class of anti-infectives. Expert Opin. Investig. Drugs 2007, 16, 1159-1169. [CrossRef]

7. Meir, O.; Zaknoon, F.; Cogan, U.; Mor, A. A broad-spectrum bactericidal lipopeptide with anti-biofilm properties. Sci. Rep. 2017, 7, 2198. [CrossRef]

8. Neubauer, D.; Jaśkiewicz, M.; Bauer, M.; Gołacki, K.; Kamysz, W. Ultrashort Cationic Lipopeptides-Effect of N-Terminal Amino Acid and Fatty Acid Type on Antimicrobial Activity and Hemolysis. Molecules 2020, 25, 257. [CrossRef]

9. Malanovic, N.; Lohner, K. Antimicrobial peptides targeting Gram-positive bacteria. Pharmaceuticals 2016, 9, 59. [CrossRef]

10. Hobden, C.; Teevan, C.; Jones, L.; O'Shea, P. Hydrophobic properties of the cell surface of Candida albicans: A role in aggregation. Microbiology 1995, 141, 1875-1881. [CrossRef]

11. Mago, N.; Khuller, G.K. Lipids of Candida albicans: Subcellular distribution and biosynthesis. J. Gen. Microbiol. 1990, 136, 993-996. [CrossRef] [PubMed]

12. Gährs, W.; Tigyi, Z.; Emody, L.; Makovitzky, J. Polarization optical analysis of the surface structures of various fungi. Acta Histochem. 2009, 111, 309-316. [CrossRef]

13. Dawgul, M.; Greber, K.; Bartoszewska, S.; Baranska-Rybak, W.; Sawicki, W.; Kamysz, W. In Vitro Evaluation of Cytotoxicity and Permeation Study on Lysine- and Arginine-Based Lipopeptides with Proven Antimicrobial Activity. Molecules 2017, 22, 2173. [CrossRef] [PubMed]

14. Armas, F.; Pacor, S.; Ferrari, E.; Guida, F.; Pertinhez, T.A.; Romani, A.A.; Scocchi, M.; Benincasa, M. Design, antimicrobial activity and mechanism of action of Arg-rich ultra-short cationic lipopeptides. PLOS ONE 2019, 14. [CrossRef] [PubMed]

15. Dawgul, M.; Maciejewska, M.; Jaskiewicz, M.; Karafova, A.; Kamysz, W. Antimicrobial peptides as potential tool to fight bacterial biofilm. Acta Pol. Pharm. 2014, 71, 39-47. [PubMed]

16. Sikorska, E.; Dawgul, M.; Greber, K.; Iłowska, E.; Pogorzelska, A.; Kamysz, W. Self-assembly and interactions of short antimicrobial cationic lipopeptides with membrane lipids: ITC, FTIR and molecular dynamics studies. Biochim. Biophys. Acta 2014, 1838, 2625-2634. [CrossRef]

17. Greber, K.E.; Dawgul, M.; Kamysz, W.; Sawicki, W. Cationic Net Charge and Counter Ion Type as Antimicrobial Activity Determinant Factors of Short Lipopeptides. Front. Microbiol. 2017, 8, 123. [CrossRef] 
18. Findlay, B.; Mookherjee, N.; Schweizer, F. Ultrashort Cationic Lipopeptides and Lipopeptoids Selectively Induce Cytokine Production in Macrophages. PLoS ONE 2013, 8, e54280. [CrossRef]

19. Li, L.; Vorobyov, I.; Allen, T.W. The different interactions of lysine and arginine side chains with lipid membranes. J. Phys. Chem. B 2013, 117, 11906-11920. [CrossRef]

20. Wu, Z.; Cui, Q.; Yethiraj, A. Why do arginine and lysine organize lipids differently? Insights from coarse-grained and atomistic simulations. J. Phys. Chem. B 2013, 117, 12145-12156. [CrossRef]

21. Góngora-Benítez, M.; Tulla-Puche, J.; Albericio, F. Multifaceted Roles of Disulfide Bonds. Peptides as Therapeutics. Chem. Rev. 2014, 114, 901-926. [CrossRef] [PubMed]

22. Li, S.; Schöneich, C.; Borchardt, R.T. Chemical instability of protein pharmaceuticals: Mechanisms of oxidation and strategies for stabilization. Biotechnol. Bioeng. 1995, 48, 490-500. [CrossRef] [PubMed]

23. Mant, C.T.; Hodges, R.S. Context-dependent effects on the hydrophilicity/hydrophobicity of side-chains during reversed-phase high-performance liquid chromatography: Implications for prediction of peptide retention behaviour. J. Chromatogr. A 2006, 1125, 211-219. [CrossRef] [PubMed]

24. Soetens, J.C.; Millot, C.; Chipot, C.; Jansen, G.; Ángyán, J.G.; Maigret, B. Effect of polarizability on the potential of mean force of two cations. The guanidimum-guanidinium ion pair in water. J. Phys. Chem. B 1997, 101, 10910-10917. [CrossRef]

25. Robison, A.D.; Sun, S.; Poyton, M.F.; Johnson, G.A.; Pellois, J.P.; Jungwirth, P.; Vazdar, M.; Cremer, P.S. Polyarginine Interacts More Strongly and Cooperatively than Polylysine with Phospholipid Bilayers. J. Phys. Chem. B 2016, 120, 9287-9296. [CrossRef]

26. Vondrášek, J.; Mason, P.E.; Heyda, J.; Collins, K.D.; Jungwirth, P. The molecular origin of like-charge arginine-Arginine pairing in water. J. Phys. Chem. B 2009, 113, 9041-9045. [CrossRef]

27. Vazdar, M.; Heyda, J.; Mason, P.E.; Tesei, G.; Allolio, C.; Lund, M.; Jungwirth, P. Arginine "magic": Guanidinium Like-Charge Ion Pairing from Aqueous Salts to Cell Penetrating Peptides. Acc. Chem. Res. 2018, 51, 1455-1464. [CrossRef]

28. Neves, M.A.C.; Yeager, M.; Abagyan, R. Unusual arginine formations in protein function and assembly: Rings, strings, and stacks. J. Phys. Chem. B 2012, 116, 7006-7013. [CrossRef]

29. Jaśkiewicz, M.; Neubauer, D.; Kamysz, W. Comparative Study on Antistaphylococcal Activity of Lipopeptides in Various Culture Media. Antibiotics 2017, 6, 15. [CrossRef]

30. McPhee, J.B.; Lewenza, S.; Hancock, R.E.W. Cationic antimicrobial peptides activate a two-component regulatory system, PmrA-PmrB, that regulates resistance to polymyxin B and cationic antimicrobial peptides in Pseudomonas aeruginosa. Mol. Microbiol. 2003, 50, 205-217. [CrossRef]

31. Gunn, J.S.; Lim, K.B.; Krueger, J.; Kim, K.; Guo, L.; Hackett, M.; Miller, S.I. PmrA-PmrB-regulated genes necessary for 4-aminoarabinose lipid A modification and polymyxin resistance. Mol. Microbiol. 1998, 27, 1171-1182. [CrossRef] [PubMed]

32. Thaipisuttikul, I.; Hittle, L.E.; Chandra, R.; Zangari, D.; Dixon, C.L.; Garrett, T.A.; Rasko, D.A.; Dasgupta, N.; Moskowitz, S.M.; Malmström, L.; et al. A divergent Pseudomonas aeruginosa palmitoyltransferase essential for cystic fibrosis-specific lipid A. Mol. Microbiol. 2014, 91, 158-174. [CrossRef]

33. King, J.D.; Kocíncová, D.; Westman, E.L.; Lam, J.S. Lipopolysaccharide biosynthesis in Pseudomonas aeruginosa. Innate Immun. 2009, 15, 261-312. [CrossRef] [PubMed]

34. Hui, C.Y.; Guo, Y.; He, Q.S.; Peng, L.; Wu, S.C.; Cao, H.; Huang, S.H. Escherichia coli outer membrane protease OmpT confers resistance to urinary cationic peptides. Microbiol. Immunol. 2010, 54, 452-459. [CrossRef] [PubMed]

35. Ulvatne, H.; Haukland, H.H.; Samuelsen, Ø.; Krämer, M.; Vorland, L.H. Proteases in Escherichia coli and Staphylococcus aureus confer reduced susceptibility to lactoferricin B. J. Antimicrob. Chemother. 2002, 50, 461-467. [CrossRef]

36. Mangoni, M.L.; Shai, Y. Short native antimicrobial peptides and engineered ultrashort lipopeptides: Similarities and differences in cell specificities and modes of action. Cell. Mol. Life Sci. 2011, 68, 2267-2280. [CrossRef] [PubMed]

37. Sikorska, E.; Stachurski, O.; Neubauer, D.; Małuch, L.; Wyrzykowski, D.; Bauer, M.; Brzozowski, K.; Kamysz, W. Short arginine-rich lipopeptides: From self-assembly to antimicrobial activity. Biochim. Biophys. Acta 2018, 1860, 2242-2251. [CrossRef]

38. Sarig, H.; Rotem, S.; Ziserman, L.; Danino, D.; Mor, A. Impact of self-assembly properties on antibacterial activity of short acyl-lysine oligomers. Antimicrob. Agents Chemother. 2008, 52, 4308-4314. [CrossRef] 
39. Stachurski, O.; Neubauer, D.; Małuch, I.; Wyrzykowski, D.; Bauer, M.; Bartoszewska, S.; Kamysz, W.; Sikorska, E. Effect of self-assembly on antimicrobial activity of double-chain short cationic lipopeptides. Bioorg. Med. Chem. 2019, 27, 115129. [CrossRef]

40. Makovitzki, A.; Baram, J.; Shai, Y. Antimicrobial lipopolypeptides composed of palmitoyl di- and tricationic peptides: In vitro and in vivo activities, self-assembly to nanostructures, and a plausible mode of action. Biochemistry 2008, 47, 10630-10636. [CrossRef]

41. Makovitzki, A.; Shai, Y. pH-Dependent Antifungal Lipopeptides and Their Plausible Mode of Action. Biochemistry 2005, 44, 9775-9784. [CrossRef] [PubMed]

42. Vylkova, S.; Li, X.S.; Berner, J.C.; Edgerton, M. Distinct antifungal mechanisms: $\beta$-defensins require Candida albicans Ssa1 protein, while Trk1p mediates activity of cysteine-free cationic peptides. Antimicrob. Agents Chemother. 2006, 50, 324-331. [CrossRef] [PubMed]

43. Schielmann, M.; Szweda, P.; Gucwa, K.; Kawczyński, M.; Milewska, M.J.; Martynow, D.; Morschhäuser, J.; Milewski, S. Transport Deficiency Is the Molecular Basis of Candida albicans Resistance to Antifungal Oligopeptides. Front. Microbiol. 2017, 8, 2154. [CrossRef] [PubMed]

44. Kumar, R.; Chadha, S.; Saraswat, D.; Bajwa, J.S.; Li, R.A.; Conti, H.R.; Edgerton, M. Histatin 5 uptake by Candida albicans utilizes polyamine transporters Dur3 and Dur31 proteins. J. Biol. Chem. 2011, 286, 43748-43758. [CrossRef] [PubMed]

45. Nagao, J.-I.; Cho, T.; Mitarai, M.; Iohara, K.; Hayama, K.; Abe, S.; Tanaka, Y. Antifungal activity in vitro and in vivo of a salmon protamine peptide and its derived cyclic peptide against Candida albicans. FEMS Yeast Res. 2017, 17, 99. [CrossRef] [PubMed]

46. Lebeaux, D.; Ghigo, J.-M.; Beloin, C. Biofilm-Related Infections: Bridging the Gap between Clinical Management and Fundamental Aspects of Recalcitrance toward Antibiotics. Microbiol. Mol. Biol. Rev. 2014, 78, 510-543. [CrossRef]

47. Maciejewska, M.; Bauer, M.; Neubauer, D.; Kamysz, W.; Dawgul, M. Influence of Amphibian Antimicrobial Peptides and Short Lipopeptides on Bacterial Biofilms Formed on Contact Lenses. Materials 2016, 9, 873. [CrossRef]

48. Rodrigues, L.; Banat, I.M.; Teixeira, J.; Oliveira, R. Biosurfactants: Potential applications in medicine. J. Antimicrob. Chemother. 2006, 57, 609-618. [CrossRef]

49. Janek, T.; Łukaszewicz, M.; Krasowska, A. Antiadhesive activity of the biosurfactant pseudofactin II secreted by the Arctic bacterium Pseudomonas fluorescens BD5. BMC Microbiol. 2012, 12, 24. [CrossRef]

50. Alves, D.; Magalhães, A.; Grzywacz, D.; Neubauer, D.; Kamysz, W.; Pereira, M.O. Co-immobilization of Palm and DNase I for the development of an effective anti-infective coating for catheter surfaces. Acta Biomater. 2016, 44, 313-322. [CrossRef]

51. Fletcher, M. The Effects of Proteins on Bacterial Attachment to Polystyrene. J. Gen. Microbiol. 1976, 94, 400-404. [CrossRef] [PubMed]

52. Toba, F.A.; Visai, L.; Trivedi, S.; Lowy, F.D. The role of ionic interactions in the adherence of the Staphylococcus epidermidis adhesin SdrF to prosthetic material. FEMS Microbiol. Lett. 2013, 338, 24-30. [CrossRef]

53. Kao, W.K.; Gagnon, P.M.; Vogel, J.P.; Chole, R.A. Surface charge modification decreases Pseudomonas aeruginosa adherence in vitro and bacterial persistence in an in vivo implant model. Laryngoscope 2017, 127, 1655-1661. [CrossRef] [PubMed]

54. Paduszynska, M.A.; Maciejewska, M.; Neubauer, D.; Golacki, K.; Szymukowicz, M.; Bauer, M.; Kamysz, W. Influence of Short Cationic Lipopeptides with Fatty Acids of Different Chain Lengths on Bacterial Biofilms Formed on Polystyrene and Hydrogel Surfaces. Pharmaceutics 2019, 11, 506. [CrossRef]

55. Efron, N.; Brennan, N.A.; Chalmers, R.L.; Jones, L.; Lau, C.; Morgan, P.B.; Nichols, J.J.; Szczotka-Flynn, L.B.; Willcox, M.D. Thirty years of 'quiet eye' with etafilcon A contact lenses. Contact Lens Anterior Eye 2020, 43, 285-297. [CrossRef] [PubMed]

56. Giacometti, A.; Cirioni, O.; Barchiesi, F.; Del Prete, M.S.; Fortuna, M.; Caselli, F.; Scalise, G. In vitro susceptibility tests for cationic peptides: Comparison of broth microdilution methods for bacteria that grow aerobically. Antimicrob. Agents Chemother. 2000, 44, 1694-1696. [CrossRef] [PubMed]

57. Laverty, G.; McLaughlin, M.; Shaw, C.; Gorman, S.P.; Gilmore, B.F. Antimicrobial Activity of Short, Synthetic Cationic Lipopeptides. Chem. Biol. Drug Des. 2010, 75, 563-569. [CrossRef]

58. Lohan, S.; Cameotra, S.S.; Bisht, G.S. Systematic Study of Non-Natural Short Cationic Lipopeptides as Novel Broad-Spectrum Antimicrobial Agents. Chem. Biol. Drug Des. 2013, 82, 557-566. [CrossRef] 
59. Hou, J.; Liu, Z.; Cao, S.; Wang, H.; Jiang, C.; Hussain, M.A.; Pang, S. Broad-Spectrum antimicrobial activity and low cytotoxicity against human cells of a peptide derived from bovine $\alpha$ S1-casein. Molecules 2018, 23, 1220. [CrossRef]

60. Avrahami, D.; Shai, Y. A New Group of Antifungal and Antibacterial Lipopeptides Derived from Non-membrane Active Peptides Conjugated to Palmitic Acid. J. Biol. Chem. 2004, 279, 12277-12285. [CrossRef]

61. Ermakova, E.; Zuev, Y. Effect of ergosterol on the fungal membrane properties. All-atom and coarse-grained molecular dynamics study. Chem. Phys. Lipids 2017, 209, 45-53. [CrossRef]

62. Lichius, A.; Zeilinger, S. Application of membrane and cell wall selective fluorescent dyes for live-cell imaging of filamentous fungi. J. Vis. Exp. 2019, 2019. [CrossRef]

63. Hickey, P.C.; Swift, S.R.; Roca, M.G.; Read, N.D. Live-cell Imaging of Filamentous Fungi Using Vital Fluorescent Dyes and Confocal Microscopy. Methods Microbiol. 2004, 34, 63-87.

64. Park, S.C.; Kim, J.Y.; Shin, S.O.; Jeong, C.Y.; Kim, M.H.; Shin, S.Y.; Cheong, G.W.; Park, Y.; Hahm, K.S. Investigation of toroidal pore and oligomerization by melittin using transmission electron microscopy. Biochem. Biophys. Res. Commun. 2006, 343, 222-228. [CrossRef] [PubMed]

65. Koike, M.; Iida, K.; Matsuo, T. Electron microscopic studies on mode of action of polymyxin. J. Bacteriol. 1969, 97, 448-452. [CrossRef] [PubMed]

66. Deris, Z.Z.; Swarbrick, J.D.; Roberts, K.D.; Azad, M.A.K.; Akter, J.; Horne, A.S.; Nation, R.L.; Rogers, K.L.; Thompson, P.E.; Velkov, T.; et al. Probing the penetration of antimicrobial polymyxin lipopeptides into gram-negative bacteria. Bioconjug. Chem. 2014, 25, 750-760. [CrossRef]

67. Arnusch, C.J.; Ulm, H.; Josten, M.; Shadkchan, Y.; Osherov, N.; Sahl, H.G.; Shai, Y. Ultrashort peptide bioconjugates are exclusively antifungal agents and synergize with cyclodextrin and amphotericin $\mathrm{B}$. Antimicrob. Agents Chemother. 2012, 56, 1-9. [CrossRef]

68. Neue, U.D.; Niederlaender, C.L.; Peterson, J.S. Liquid Chromatography Stationary Phases with Reduced Silanol Interactions. U.S. Patent US5374755A, 20 December 1994.

69. Clinical and Laboratory Standards Institute (CLSI). Methods for Dilution Antimicrobial Susceptibility Tests for Bacteria That Grow Aerobically; Approved Standard, 9th ed.; CLSI: Wayne, PA, USA, 2012; Volume 32, ISBN 1562387839.

70. Clinical and Laboratory Standards Institute (CLSI). Reference Method for Broth Dilution Antifungal Susceptibility Testing of Yeasts: Approved Standards, 2nd ed.; CLSI Document M27-2A 2002; CLSI: Wayne, PA, USA, 2002; Volume 22, ISBN 1562384694.

71. Jones, R.N.; Wilson, H.W.; Novick, W.J.; Barry, A.L.; Thornsberry, C. In vitro evaluation of CENTA, a new beta-lactamase-susceptible chromogenic cephalosporin reagent. J. Clin. Microbiol. 1982, 15, 954-958. [CrossRef]

72. Abbassi, F.; Lequin, O.; Piesse, C.; Goasdoué, N.; Foulon, T.; Nicolas, P.; Ladram, A. Temporin-SHf, a new type of phe-rich and hydrophobic ultrashort antimicrobial peptide. J. Biol. Chem. 2010, 285, 16880-16892. [CrossRef]

73. Arcidiacono, S.; Soares, J.W.; Meehan, A.M.; Marek, P.; Kirby, R. Membrane permeability and antimicrobial kinetics of cecropin P1 against Escherichia coli. J. Pept. Sci. 2009, 15, 398-403. [CrossRef]

74. Ilić, N.; Novković, M.; Guida, F.; Xhindoli, D.; Benincasa, M.; Tossi, A.; Juretić, D. Selective antimicrobial activity and mode of action of adepantins, glycine-rich peptide antibiotics based on anuran antimicrobial peptide sequences. Biochim. Biophys. Acta 2013, 1828, 1004-1012. [CrossRef] [PubMed]

75. Romani, A.A.; Baroni, M.C.; Taddei, S.; Ghidini, F.; Sansoni, P.; Cavirani, S.; Cabassi, C.S. In vitro activity of novel in silico -developed antimicrobial peptides against a panel of bacterial pathogens. J. Pept. Sci. 2013, 19, 554-565. [CrossRef] [PubMed]

76. Periole, X.; Marrink, S.-J. The Martini Coarse-Grained Force Field. In Biomolecular Simulations; Humana Press: Totowa, NJ, USA, 2013; pp. 533-565.

77. Marrink, S.J.; Risselada, H.J.; Yefimov, S.; Tieleman, D.P.; De Vries, A.H. The MARTINI force field: Coarse grained model for biomolecular simulations. J. Phys. Chem. B 2007, 111, 7812-7824. [CrossRef] [PubMed]

78. Hess, B.; Kutzner, C.; Van Der Spoel, D.; Lindahl, E. GRGMACS 4: Algorithms for highly efficient, load-balanced, and scalable molecular simulation. J. Chem. Theory Comput. 2008, 4, 435-447. [CrossRef] [PubMed] 
79. Chugunov, A.; Pyrkova, D.; Nolde, D.; Polyansky, A.; Pentkovsky, V.; Efremov, R. Lipid-II forms potential "landing terrain" for lantibiotics in simulated bacterial membrane. Sci. Rep. 2013, 3, 1678. [CrossRef] [PubMed]

80. Winger, M.; Trzesniak, D.; Baron, R.; Van Gunsteren, W.F. On using a too large integration time step in molecular dynamics simulations of coarse-grained molecular models. Phys. Chem. Chem. Phys. 2009, 11, 1-8. [CrossRef]

81. Gapsys, V.; de Groot, B.L.; Briones, R. Computational analysis of local membrane properties. J. Comput. Aided Mol. Des. 2013, 27, 845-858. [CrossRef]

82. Humphrey, W.; Dalke, A.; Schulten, K. VMD: Visual molecular dynamics. J. Mol. Graph. 1996, 14, $33-38$. [CrossRef]

83. Eckhard, L.H.; Houri-Haddad, Y.; Sol, A.; Zeharia, R.; Shai, Y.; Beyth, S.; Domb, A.J.; Bachrach, G.; Beyth, N. Sustained Release of Antibacterial Lipopeptides from Biodegradable Polymers against Oral Pathogens. PLOS ONE 2016, 11, e0162537. [CrossRef]

84. Yim, V.V.; Kavianinia, I.; Cameron, A.J.; Harris, P.W.R.; Brimble, M.A. Direct synthesis of cyclic lipopeptides using intramolecular native chemical ligation and thiol-ene CLipPA chemistry. Org. Biomol. Chem. 2020, 18, 2838-2844. [CrossRef]

85. Knerr, P.J.; Tzekou, A.; Ricklin, D.; Qu, H.; Chen, H.; Van Der Donk, W.A.; Lambris, J.D. Synthesis and activity of thioether-containing analogues of the complement inhibitor compstatin. ACS Chem. Biol. 2011, 6, 753-760. [CrossRef] [PubMed]

86. Davies, J.S. The cyclization of peptides and depsipeptides. J. Pept. Sci. 2003, 9, 471-501. [CrossRef] [PubMed]

87. Tsubery, H.; Ofek, I.; Cohen, S.; Fridkin, M. Structure-Function studies of Polymyxin B nonapeptide: Implications to sensitization of Gram-negative bacteria. J. Med. Chem. 2000, 43, 3085-3092. [CrossRef] [PubMed]

88. Ballantine, R.D.; Li, Y.X.; Qian, P.Y.; Cochrane, S.A. Rational design of new cyclic analogues of the antimicrobial lipopeptide tridecaptin A1. Chem. Commun. 2018, 54, 10634-10637. [CrossRef] [PubMed]

89. Jelokhani-Niaraki, M.; Kondejewski, L.H.; Wheaton, L.C.; Hodges, R.S. Effect of ring size on conformation and biological activity of cyclic cationic antimicrobial peptides. J. Med. Chem. 2009, 52, 2090-2097. [CrossRef]

90. Mulder, M.P.C.; Kruijtzer, J.A.W.; Breukink, E.J.; Kemmink, J.; Pieters, R.J.; Liskamp, R.M.J. Synthesis and evaluation of novel macrocyclic antifungal peptides. Bioorganic Med. Chem. 2011, 19, 6505-6517. [CrossRef] 